ARTICLE

https://doi.org/10.1038/s41467-018-07949-6

\title{
A tRNA half modulates translation as stress response in Trypanosoma brucei
}

\author{
Roger Fricker ${ }^{1,2}$, Rebecca Brogli1 ${ }^{1,2}$, Hannes Luidalepp ${ }^{1}$, Leander Wyss ${ }^{1,2}$, Michel Fasnacht ${ }^{1,2}$, Oliver Joss ${ }^{1}$,
} Marek Zywicki ${ }^{3}$, Mark Helm (10 ${ }^{4}$, André Schneider ${ }^{1}$, Marina Cristodero ${ }^{1}$ \& Norbert Polacek ${ }^{1}$

In the absence of extensive transcription control mechanisms the pathogenic parasite Trypanosoma brucei crucially depends on translation regulation to orchestrate gene expression. However, molecular insight into regulating protein biosynthesis is sparse. Here we analyze the small non-coding RNA (ncRNA) interactome of ribosomes in T. brucei during different growth conditions and life stages. Ribosome-associated ncRNAs have recently been recognized as unprecedented regulators of ribosome functions. Our data show that the tRNA ${ }^{\text {Thr }} 3$ 'half is produced during nutrient deprivation and becomes one of the most abundant tRNAderived RNA fragments (tdRs). tRNA Thr halves associate with ribosomes and polysomes and stimulate translation by facilitating mRNA loading during stress recovery once starvation conditions ceased. Blocking or depleting the endogenous tRNAThr halves mitigates this stimulatory effect both in vivo and in vitro. T. brucei and its close relatives lack the welldescribed mammalian enzymes for tRNA half processing, thus hinting at a unique tdR biogenesis in these parasites.

\footnotetext{
${ }^{1}$ Department of Chemistry and Biochemistry, University of Bern, Freiestrasse 3, 3012 Bern, Switzerland. ${ }^{2}$ Graduate School for Cellular and Biomedical Sciences, University of Bern, 3012 Bern, Switzerland. ${ }^{3}$ Department of Computational Biology, Institute of Molecular Biology and Biotechnology, Adam Mickiewicz University, Umultowska 89, 61-614 Poznan, Poland. ${ }^{4}$ Institute of Pharmacy and Biochemistry, Johannes Gutenberg-University of Mainz, Staudingerweg 5, D-55128 Mainz, Germany. These authors contributed equally: Roger Fricker, Rebecca Brogli. Correspondence and requests for materials should be addressed to M.C. (email: marina.cristodero@dcb.unibe.ch) or to N.P. (email: norbert.polacek@dcb.unibe.ch)
} 
T he pathogenic protozoan parasite Trypanosoma brucei and its relatives are causative agents of human African trypanosomiasis in sub-Saharan regions and other devastating diseases that are difficult to treat. T. brucei has a complex life cycle involving two different hosts, an insect and a mammal, and possesses clearly distinguishable developmental stages ${ }^{1}$. Despite the fact that this protozoan organism has to adapt to different environments it largely lacks the ability to regulate transcription of protein coding genes. Therefore, and in contrast to other eukaryotes, they heavily rely on posttranscriptional means to regulate gene expression ${ }^{2}$. At first sight, the lack of transcriptional control seems to be energetically wasteful, but it may help the trypanosomes to react faster to environmental challenges and can even be beneficial during host transmission ${ }^{3}$. While well understood posttranscriptional mechanisms of gene regulation such as the RNAi pathways are at work in most eukaryotes, miRNAguided translation regulation seems to be absent in trypanosomes ${ }^{4}$. Even though translation control is pivotal for the regulation of gene expression in T. brucei ${ }^{5}$ there is little information about how these parasites regulate protein biosynthesis at the molecular level. Recently we have identified ribosome-associated ncRNAs (rancRNAs) in the archaeon H. volcanii ${ }^{6,7}$ and in Saccharomyces cerevisiae ${ }^{8}$ as potent agents involved in translation control mechanisms. RancRNAs represent an emerging class of translation regulators acting primarily during stress response and include small as well as long ncRNAs (reviewed in ref. ${ }^{9}$ ). Over the past years rancRNAs have been identified as riboregulators in all domains of life. The main advantage of rancRNA-mediated translation control is its immediate availability, since the regulatory entity is a small RNA typically derived from already existing RNA species and capable of targeting the ribosome as the main component of the translation machinery.

In order to investigate if rancRNAs play crucial roles in $T$. brucei we have analyzed the small ncRNA interactome of ribosomes isolated from two different developmental stages of the parasites exposed to different environmental conditions. We reveal tRNA halves as one of the most strongly affected classes of transcripts upregulated during nutrient deprivation and stationary phase. In particular, the abundance of the tRNA ${ }^{\text {Thr }} 3^{\prime}$ half is significantly increased and it was found to interact with ribosomes and polysomes upon starvation. This particular tRNA halfribosome interaction stimulates protein biosynthesis in vitro as well as in vivo and appears to play a role primarily during the stress recovery phase of $T$. brucei.

\section{Results}

Ribosome-associated ncRNAs in T. brucei. To gain insight into the composition and putative biological function of the emerging class of rancRNAs ${ }^{9}$, we generated a cDNA library encoding small RNAs in the size range between 20 and 300 nucleotides that copurify with cytosolic ribosomes in T. brucei. To this end ribosomes and polysomes from the procyclic as well as from the bloodstream forms of $T$. brucei cells in the exponential and stationary phases were collected. In addition, ribosomes were isolated for rancRNA identification from procyclic cells after heat shock, cold shock or nutritional stress. Subsequent to deep sequencing analysis the obtained reads were analyzed using a modified version of the previously established APART pipeline ${ }^{10}$. After trimming the adaptor sequences and quality control 30.1 million reads remained (in average 5 million reads per cDNA library) that were further analyzed and resulted in 3596 putative rancRNA candidates. All sequencing reads can be accessed via the European Nucleotide Archive number PRJEB24915. The majority of the sequencing reads mapped to ribosomal RNA loci, which is not surprising given the fact that the $28 \mathrm{~S}$ rRNA of $T$. brucei ribosomes is naturally split into six fragments, most of them in the size range under investigation. The second largest pool of sequences mapped to tRNA loci (Fig. 1a). By comparing the distribution of mapped reads between the different growth or stress conditions, it was evident that upon nutrient deprivation and during the stationary phase tRNA-derived reads became a very abundant species and dominated the sequenced rancRNA pool (Fig. 1a). Detailed information on all tRNA-derived sequencing reads are compiled in Supplementary Data 1. Length distribution of tRNA-derived reads revealed a clear peak at around 33 nucleotides, which primarily represents tRNA halves (Fig. 1b). By analyzing the abundance levels of tRNA halves across different growth conditions a significantly high correlation became evident between samples originating from heat shock, cold shock and exponentially growing $T$. brucei samples on the one side and starved and stationary cells on the other (Fig. 1c). Furthermore this analyses revealed tRNA-fragment abundance levels isolated from bloodstream form samples to be very distinct from all others and indicate a unique expression pattern, including a distinct fraction of 21 nucleotides long tRNA fragments (Fig. 1b, c). tRNAs carry multiple post-transcriptional modifications, which can hamper reverse transcription during cDNA library preparation and thus could potentially skew conclusions about tRNA fragment lengths and cellular abundance. In order to circumvent this potential limitation and to validate the rancRNA-seq data we performed comprehensive tRNA halves northern blot analyses on total RNA isolated from T. brucei exposed to different stress conditions. The results support the sequencing data by showing different levels of tRNA halves for almost all tRNA isoacceptors (Supplementary Figure 1). These experiments reveal that most of the detectable tRNA halves originate from the $5^{\prime}$ part of tRNAs and thus further confirm the sequencing data. In these northern analyses we noticed tRNA processing into halves as a consequence of different growth and stress condition to be tRNA species-dependent and thus quite heterogeneous (Supplementary Figure 1).

The abundance of tRNA halves varies during stress. To test which of these tRNA halves also associate with ribosomes, we repeated the northern blot analyses on the crude ribosome pellet. Since the sequencing and northern blot data indicated most abundant tRNA processing into halve-mers under nutrient deprivation (after incubating cells in PBS or during stationary phase), we compared ribosomes isolated from starved and exponentially growing $T$. brucei cultures (Fig. 1d). At least ten tRNA halves could be clearly detected on these northern blots. Among these potentially ribosome-associated tRNA fragments the tRNA Thr $3^{\prime}$ half as well as the two $5^{\prime}$ halves originating from tRNA Ala and tRNA ${ }^{\text {Asp }}$ were the most abundant ones (Fig. 1d) and showed differential cellular expression during the growth conditions tested (Supplementary Figure 1). We first focused on the $3^{\prime}$ tRNA half deriving from the tRNA ${ }^{\text {Thr }}$ isoacceptor harboring the AGU anticodon (Tb427_10_tRNA_Thr_1). Based on the sequencing reads, this half is particularly abundant during nutrient deprivation and in stationary phase (Supplementary Data 1, Supplementary Figure 2a). Northern blot analysis confirmed this abundance pattern and demonstrated that the $3^{\prime}$ tRNA $^{\text {Thr }}$ half accumulates in a time dependent manner in procyclic T. brucei cells during starvation and in late stationary phase (Fig. 2a, b). The time point of the first tRNA ${ }^{\text {Thr }} 3^{\prime}$ half detection (two hours of nutrient deprivation) coincides with moving impairment of T. brucei cells. Placing the starved cells back into normal growth media results in resumed flagellum movement after $30 \mathrm{~min}$ whereas the tRNA ${ }^{\text {Thr }}$ half remained at constant levels during this recovery phase for up to $2 \mathrm{~h}$ (Fig. $2 \mathrm{c}$ ). 

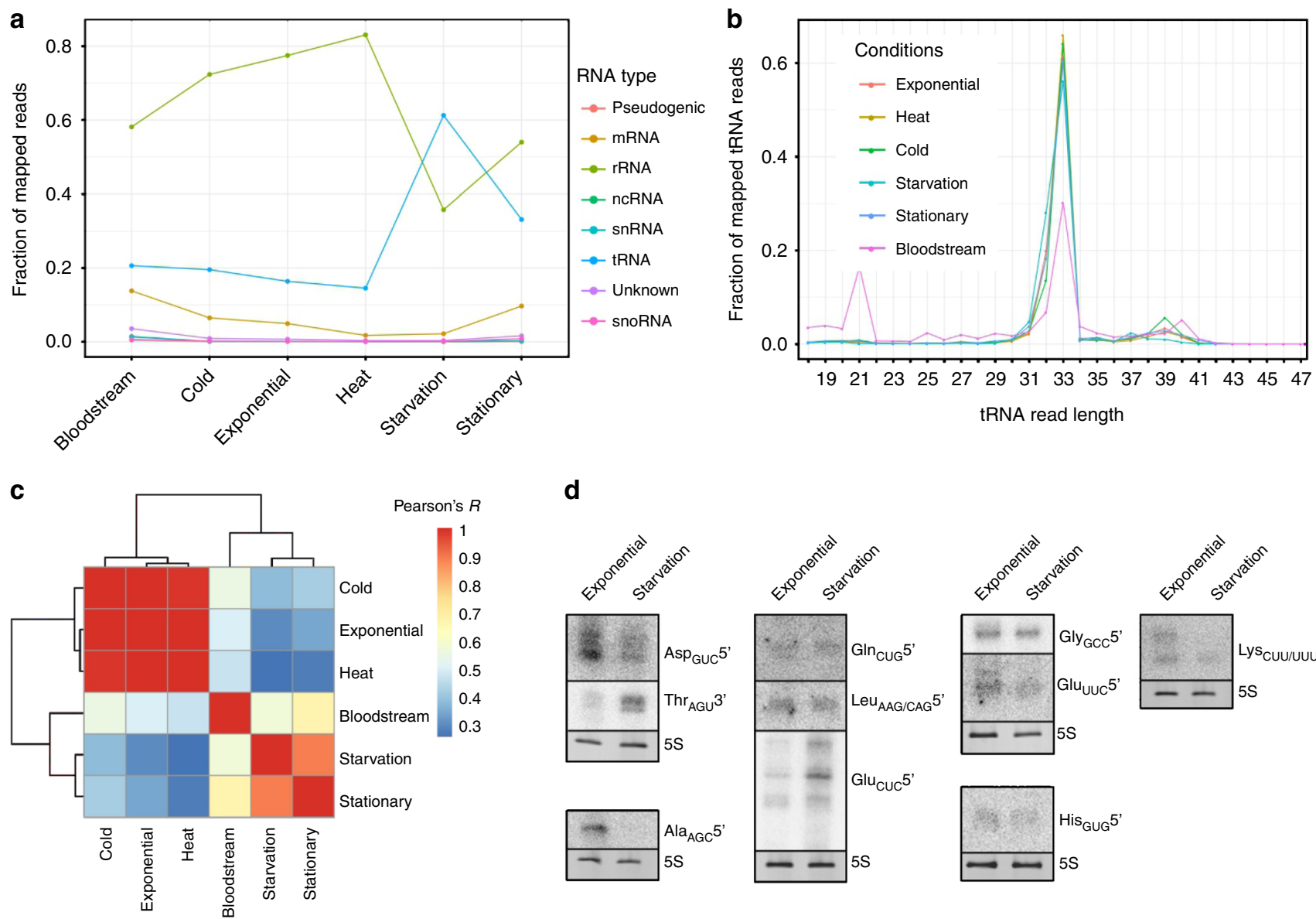

d
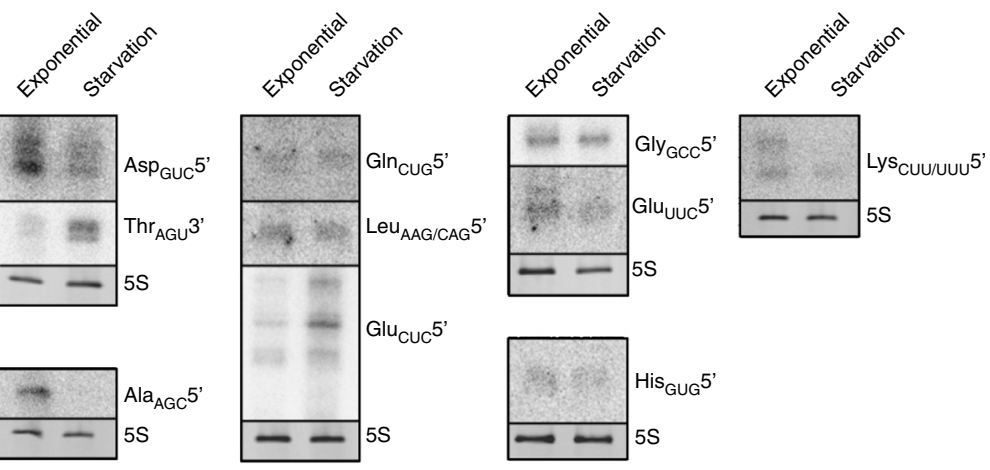

Fig. 1 Profiling the abundance levels of rancRNA sequencing reads. a The distribution of sequencing reads fractions assigned to different RNA classes among different growth conditions and life stages of T. brucei. Note that the category 'ncRNA' includes annotated T. brucei ncRNAs not listed otherwise. b Read length distribution of tRNA-derived sequencing reads observed during different growth conditions. c Sample correlation matrix showing Pearson's correlation of expression levels of identified tRNA processing products between different growth conditions and life stages. $\mathbf{d}$ Ribosome-association of tRNA halves was assessed via northern blot analyses on RNA isolated from the crude ribosomal pellet from exponentially growing cells or from cells starved for two hours by incubating the parasite in PBS. The 5S rRNA (5S) served as loading control. tRNA isoacceptor anticodons and the origin of the tRNA halve $\left(5^{\prime}\right.$ or $\left.3^{\prime}\right)$ are indicated

In northern blots we noticed a slower migrating band above the mature tRNA ${ }^{\mathrm{Thr}}$ in starved cells that rapidly disappears during the recovery phase (Fig. 2). Against intuition, this slower migrating RNA band corresponds to the tRNA ${ }^{\text {Thr }}$ lacking the $3^{\prime}$ CCA end (Supplementary Figure 3a, b). It is of note that almost all sequencing reads originating from tRNA ${ }^{\text {Thr }}$ also lack the $3^{\prime}$ CCA ends during nutritional stress (Supplementary Figure 2b). This $3^{\prime}$ tRNA trimming is in fact a widespread phenomenon under nutrient deprivation in T. brucei (Supplementary Figure 1a) and thus potentially analogous to oxidatively stressed human tRNAs ${ }^{11}$. Under the starvation conditions applied (PBS incubation for at least $2 \mathrm{~h}$ ) new tRNA transcription is likely negligible suggesting that tRNA halves are produced during nutritional stress from mature tRNAs lacking the $3^{\prime}$ CCA.

A different $\mathrm{tRNA}^{\mathrm{Thr}}$ half abundance pattern was observed in the bloodstream form of T. brucei. In contrast to the procyclic stage, which is the most prevalent form in the insect host, the tRNA ${ }^{\text {Thr }} 3^{\prime}$ half is already present during exponential growth in the bloodstream form of the parasite. The tRNA half level in the bloodstream form remained constant during starvation and during the recovery phase (Fig. 2d).

Compared to the $3^{\prime}$ tRNA $^{\text {Thr }}$ half, a completely different expression pattern was evident for the tRNA ${ }^{\text {Ala }} 5^{\prime}$ half (Tb427.07.6821) (Supplementary Figure 1). It is present in easily detectable amounts during exponential growth in the procyclic as well as in the bloodstream form, while it is undetectable during starvation conditions in both forms of the parasite (Fig. 3a, b). Alleviating the nutrient deprivation by transferring the cells back into rich media resulted in the fast reappearance of the tRNA ${ }^{\text {Ala }}$ half within 15 to $30 \mathrm{~min}$. Also during the stationary growth phase this $5^{\prime}$ tRNA half declines in abundance as a function of increased cell density (Fig. 3c). This indicates that fragment accumulation is tRNA-specific and again further suggests that tRNA halves are not unspecific degradation intermediates.

tRNA halves associate with ribosomes and polysomes. Since we discovered the tRNA halves in an RNA-seq library designed to identify rancRNAs we next investigated whether the identified tRNA halves have affinity for ribosomal particles. Therefore polysome profiles of exponentially growing procyclic cells and cells starved for two hours were recorded in linear sucrose gradients. During starvation conditions the polysomes were markedly reduced and monosomes and ribosomal subunit peaks were increased compared to the exponential growing control (Fig. 4a). This indicates reduced translational rates and dimmed overall metabolic activities under growth conditions where nutrients are limiting. Fractions of the polysome gradients were collected, the 

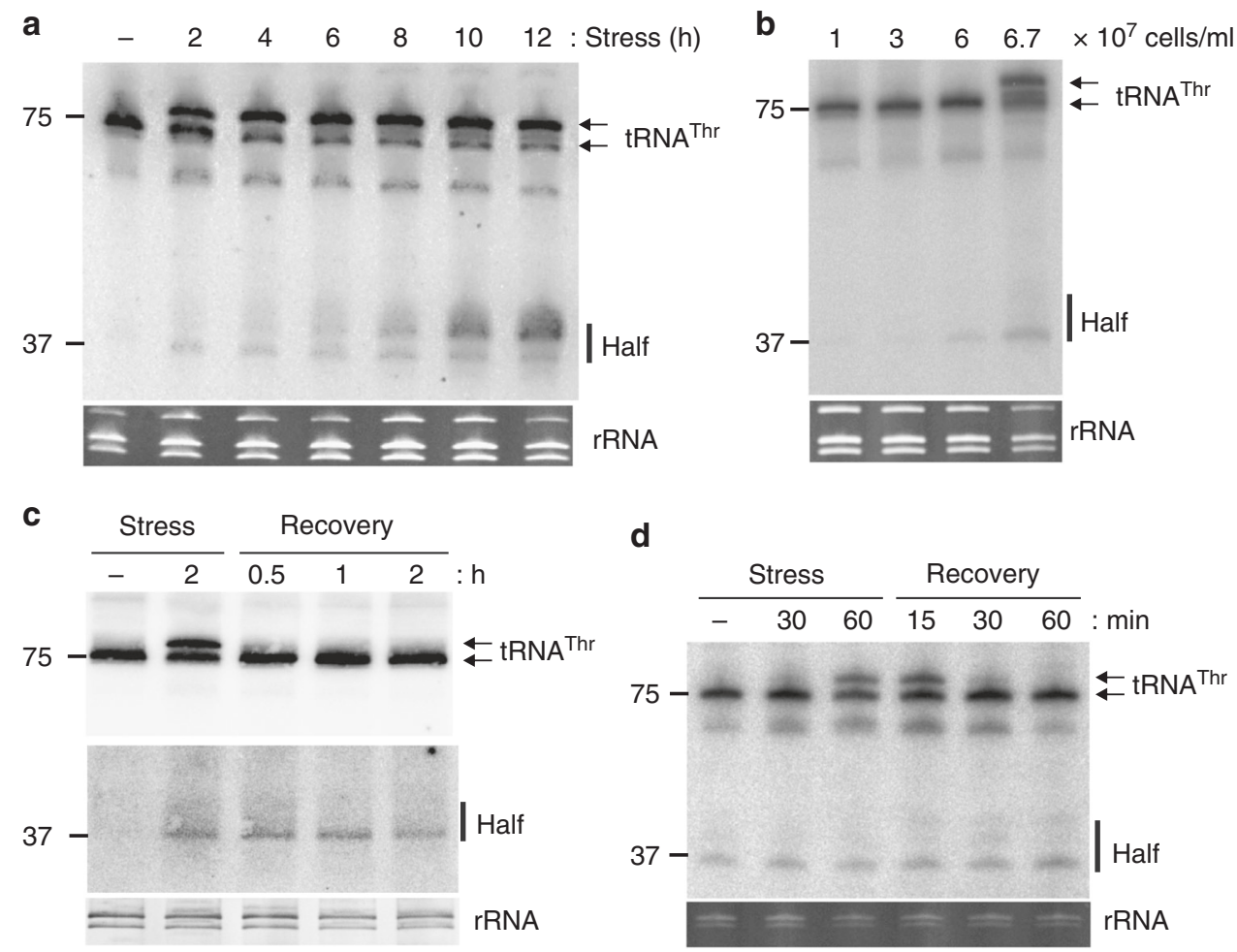

Fig. 2 tRNA ${ }^{T h r} 3^{\prime}$ half accumulates during stress in procyclic and bloodstream T. brucei. a T. brucei procyclic cells were starved for the indicated times by incubation in PBS. Total RNA was extracted and the presence of the tRNA Thr $3^{\prime}$ half (37 nucleotides long; see also Supplementary Figure 10) monitored by northern blot analysis. $\mathbf{b}$ The presence of the tRNA ${ }^{\text {Thr }} 3^{\prime}$ half was investigated as in $\mathbf{a}$ in procyclic cells grown to different cell densities (indicated on top of the panel). c Same as a but cells were allowed to recover in normal media for the indicated periods of time after nutritional stress. In the lower panel the contrast of this part of the blot was adjusted to more clearly see the tRNA Thr $3^{\prime}$ half. $\mathbf{d}$ T. brucei bloodstream cells were stressed by incubation in PBS and then allowed to recover in normal growth media. The presence of the tRNAThr $3^{\prime}$ half was analyzed as described in $\mathbf{a}$. In all cases the EtBr-stained rRNAs serve as loading controls

RNA isolated and used for northern blotting. When probing for the tRNA ${ }^{\text {Thr }} 3^{\prime}$ half after nutritional stress, signals were detected in the fractions corresponding to the large ribosomal subunit $(60 \mathrm{~S})$, the monosomes (80S), the polysomes and in light fractions at the top of the gradient (free RNA) (Fig. $4 \mathrm{~b}$ ). This indicates that the tRNA ${ }^{\text {Thr }}$ half indeed associates with ribosomes in vivo and its binding site apparently resides in the large ribosomal subunit. Even though the amount of polysomes in the sucrose gradient of starved cells is below the limit of the applied detection system (Fig. 4a), a clearly visible tRNA ${ }^{\text {Thr }}$ half signal was detectable on northern blots (Fig. 4b). This indicates that a fraction of tRNA halves accumulates on the few polysomes that are present in starved cells. Quantification of the northern blot signals corresponding to the full-length tRNA ${ }^{\text {Thr }}$ and the tRNA Thr $3^{\prime}$ half in the polysomal fraction demonstrated that $55 \%$ of the signal derives from the tRNA half-mer. In human cells it was reported that certain tRNA halves promote stress granule (SG) formation and even become integral to the stress granules ${ }^{12,13}$. SG formation is not only beneficial for survival during challenging conditions but also for recovery from stress ${ }^{14}$. Therefore, we were interested if the T. brucei $\mathrm{tRNA} \mathrm{Thr}^{\mathrm{T}} 3^{\prime}$ half modulates SG formation and/or turnover. For this purpose, we used a cell line expressing the YFP-tagged granule marker DHH1 (ref. ${ }^{15}$ ) and followed the assembly of SGs in the presence of the tRNA The $3^{\prime}$ half. After two hours of starvation stress granules were readily observed in the parasite (Supplementary Figure 4). However, stress granule formation does not appear to correlate with tRNA $^{\text {Thr }}$ halves abundance in $T$. brucei, since increasing its intracellular concentration by electroporation of $3^{\prime}$ half transcripts did not influence stress granule formation or stability
(Supplementary Figure 4). Furthermore, in the sucrose gradients stress granules do not co-sediment with the ribosome or polysome fractions under the applied conditions (Fig. 4c). These findings support the view that $\mathrm{tRNA}^{\mathrm{Thr}} 3^{\prime}$ halves (i) do not modulate genuine stress granule formation in T. brucei but (ii) bind to ribosomes and polysomes in vivo. To corroborate ribosome association we performed in vitro binding studies using gradient-purified $T$. brucei $80 \mathrm{~S}$ ribosomes isolated either from exponentially growing or from starved cells. In these binding experiments ribosome association could be confirmed and furthermore a preferential interaction of the tRNA half with stressed ribosomes was observed (Fig. 4d).

The tRNA ${ }^{\text {Thr }}$ half stimulates $T$. brucei translation. Having established a ribosome-association of the tRNA ${ }^{T h r} 3^{\prime}$ half we next tested whether this interaction has a functional consequence on the ribosomes' performance. Therefore, we established an in vitro translation assay with $T$. brucei cell extracts using the total endogenous mRNA pool as template and ${ }^{35} \mathrm{~S}$-methionine incorporation into proteins as readout (Fig. 5a). In the presence of the ribosome-targeting antibiotic puromycin all radiolabeled bands were drastically reduced demonstrating that the ${ }^{35} \mathrm{~S}$-methionine labeling of proteins was translation dependent. When the assay was performed in the presence of in vitro transcribed tRNA Thr $3^{\prime}$ halves we observed a slight but reproducible stimulatory effect on translation of about $20 \%$ (Fig. 5a). However, $\mathrm{tRNA}^{\mathrm{Thr}} 3^{\prime}$ halves containing the CCA-tail (a species that was not detected in our bioinformatics analyses; Supplementary Figure 2b) were unable to stimulate translation. To investigate if the failure of translation 

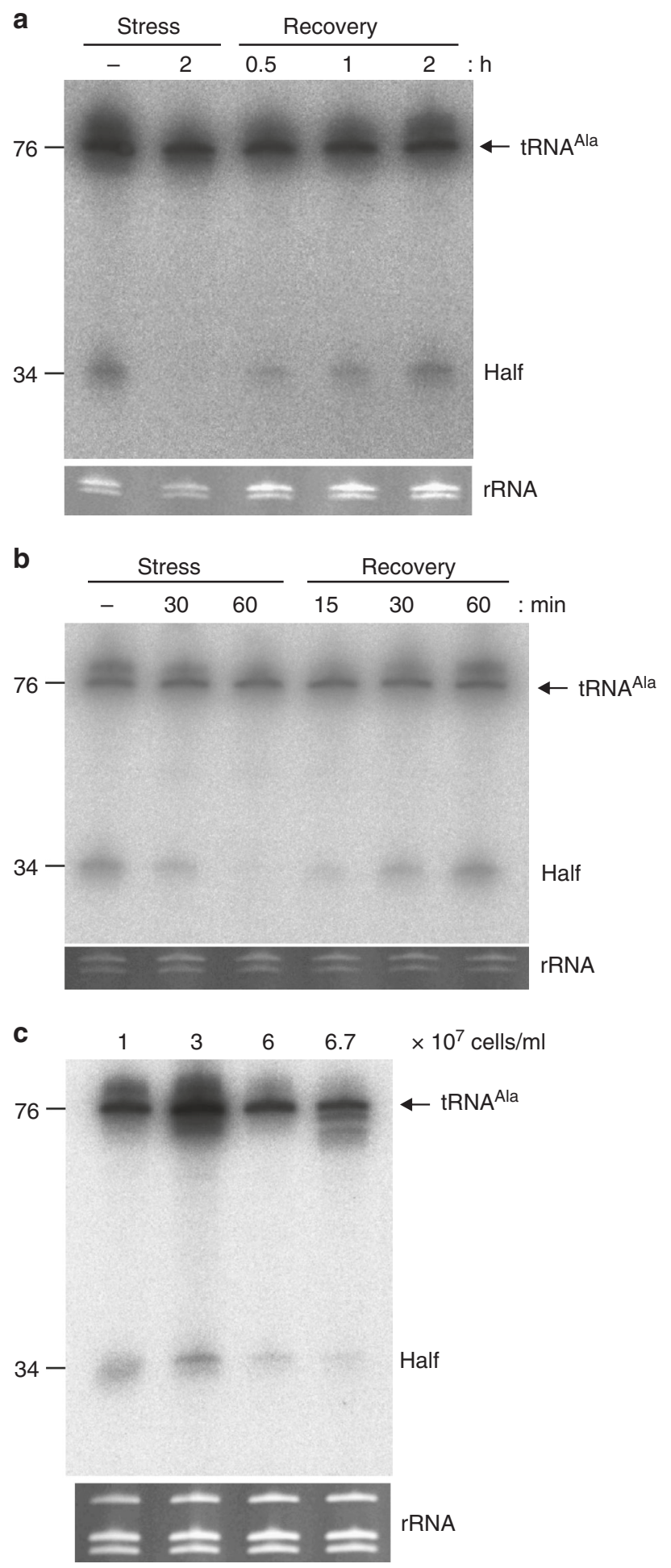

stimulation by this $3^{\prime}$ extension is CCA sequence dependent or simply length dependent, we repeated the assay with a tRNA ${ }^{\mathrm{Th}}$ half carrying the sequence GGU at its $3^{\prime}$ end. Also this molecule was unable to stimulate protein synthesis in vitro thus pointing towards a length limitation effect (Fig. 5a). Furthermore, the addition of the tRNA ${ }^{\text {Ala }} 5^{\prime}$ half or the $3^{\prime}$ half originating from tRNA Asp had no influence on in vitro protein synthesis (Fig. 5a, Supplementary Figure 5). Both of the latter results serve as specificity controls for the stimulatory effect of the tRNA ${ }^{\text {Thr }} 3^{\prime}$ half.
Fig. 3 tRNA Ala $5^{\prime}$ half is present under normal growth but disappears upon stress in procyclic and bloodstream $T$. brucei. a $T$. brucei procyclic cells were starved for two hours by incubation in PBS. Subsequently, the cells were allowed to recover in normal media for the indicated periods of time. Total RNA was extracted and the presence of the tRNA Ala $5^{\prime}$ half (length: 34 nucleotides) monitored by northern blot analysis. b $T$. brucei bloodstream cells were stressed by incubation in PBS for 30 or 60 min and then allowed to recover in normal growth media. The presence of the tRNA ${ }^{\text {Ala }} 5^{\prime}$ half was analyzed as described in a. c The presence of the tRNAAla $5^{\prime}$ half was investigated as in $\mathbf{a}$ in procyclic cells grown to different cell densities (indicated on top of the panel). In all cases the EtBr-stained rRNAs serve as loading controls

To investigate whether these in vitro effects have a physiological significance in the parasite we used electroporation to introduce synthetic tRNA halves into T. brucei cells. Conditions for small RNAs electroporation were optimized by using an siRNA (siRNA315) targeting a-tubulin ${ }^{16}$, which was shown to cause a morphological phenotype (the so called FAT cells) due to the accumulation of multiple nuclei because of incomplete cytokinesis $^{17}$. The phenotype was observed $18 \mathrm{~h}$ after electroporation and, under our optimized electroporation conditions, $71 \%$ of cells displayed the FAT phenotype (Supplementary Figure 6).

We next introduced in vitro transcribed tRNA ${ }^{\mathrm{Thr}}$ halves into $T$. brucei cells. Northern blot analysis performed two hours after electroporation demonstrated easily detectable amounts of the in vitro transcribed tRNA halves inside the cells (Supplementary Figure 7a). Omitting the electroporation step resulted in the complete loss of the northern blot signal thus demonstrating that the in vitro transcripts were indeed introduced into the cell (Supplementary Figure 7b). Subsequent to electroporation the cells were incubated under nutrient deprivation conditions and finally transferred back to full media for recovery. ${ }^{35} \mathrm{~S}$-methionine incorporation was then assessed during the stress recovery phase. Under these conditions we observed a noticeably increased translational activity in the presence of the tRNA Thr $3^{\prime}$ half of about 35\% (Fig. 5b). As previously seen in vitro, addition of CCA or GGU to the $3^{\prime}$ end of the tRNA half eliminated translation stimulation, thus showing the specificity of the tRNA ${ }^{\mathrm{Thr}} 3^{\prime}$ half effect. While the length of the tRNA ${ }^{\text {Thr }} 3^{\prime}$ half appears to be critical, the chemical identity of the $5^{\prime}$ end seems to be less crucial. Halves containing a mono- or a triphosphate were equally able to stimulate translation in vivo (Fig. 5c). Similar to the in vitro translation assay, the tRNA ${ }^{\text {Ala }} 5^{\prime}$ half had no effect in vivo (Fig. $5 \mathrm{~b}$ ).

tRNAs carry multiple post-transcriptional nucleoside modifications whose biological roles in translation and beyond are only beginning to be understood (ref. ${ }^{18}$ and references therein). Even the regulatory role of a tRNA-derived fragment in human stem cells has recently been shown to depend on a post-transcriptional modification $^{19}$. The involvement of modified nucleosides in the biology of tRNA-derived fragments however cannot be generalized. The fact that in vitro transcribed tRNA ${ }^{T h r} 3^{\prime}$ halves stimulate translation in vivo (Fig. 5b, c) excludes pivotal roles of modifications on that molecule for this particular function. Support for this conclusion comes from LC-MS/MS-based analyses of affinity purified tRNA ${ }^{\mathrm{Thr}}$ from unstressed and starved T. brucei cells by a neutral-loss scan approach ${ }^{20}$. This RNA mass spectrometry data showed highly similar modification profiles without significant differences (Supplementary Figure 8). Thus these findings do not leave any basis to suspect tRNA ${ }^{T h r}$ nucleoside modifications for being fundamental for the stressdependent production of the $3^{\prime}$ half and for the observed stimulatory role during translation in vivo and in vitro.

Since both tRNAs and ribosomes are highly conserved components of the translational machinery, we next tested if 
a

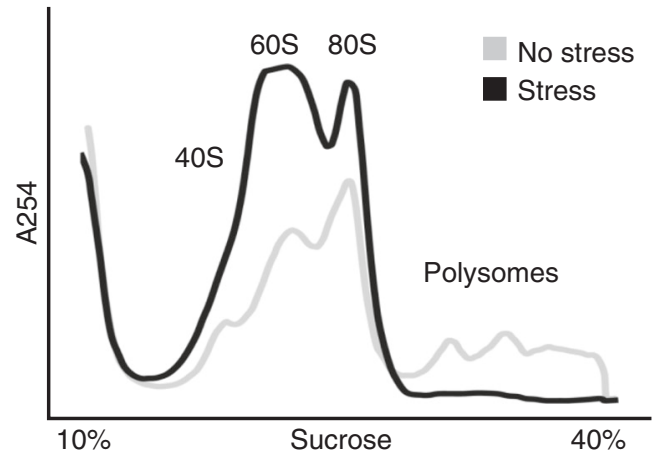

C

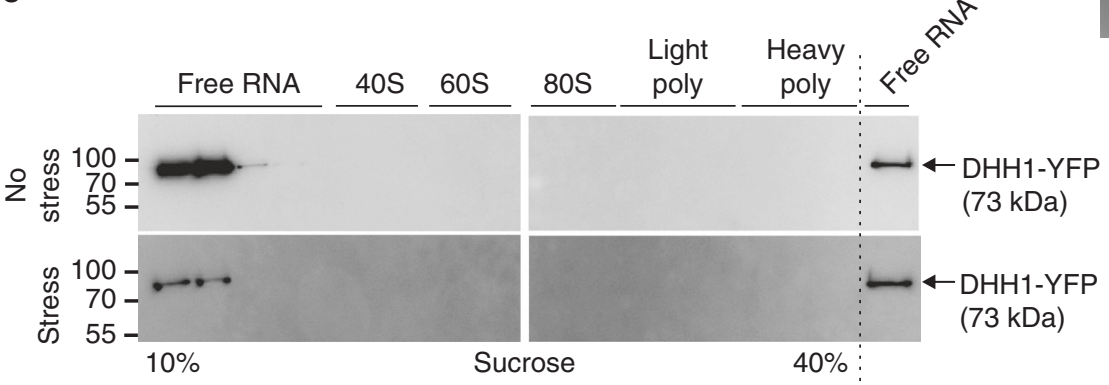

b

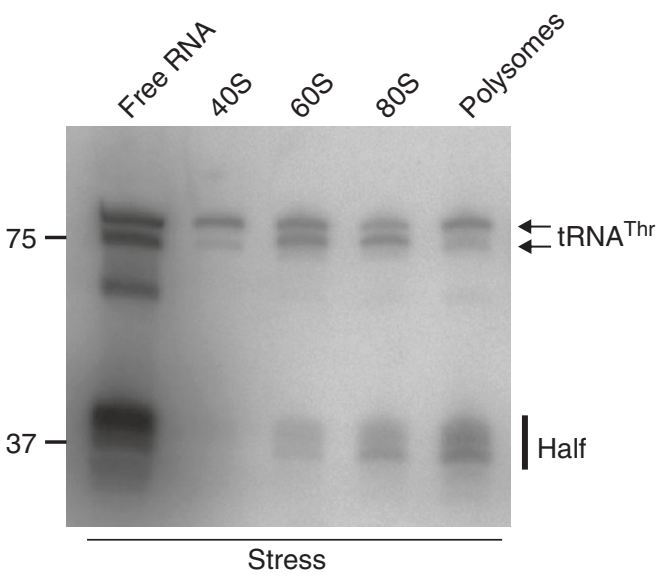

d

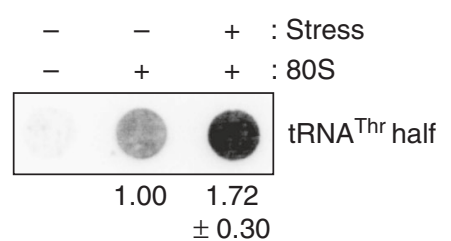

Fig. 4 The tRNAThr $3^{\prime}$ half associates with ribosomes in vivo and in vitro. a Polysome profiling with sucrose gradients (10-40\%) using total cell lysates prepared from exponentially growing T. brucei cells (gray) and from cells starved for $2 \mathrm{~h}$ in PBS (black). b RNA was extracted from fractions containing polysomes, $80 \mathrm{~S}$ monosomes, $60 \mathrm{~S}$, or $40 \mathrm{~S}$ ribosomal subunits and from the light sucrose gradient fractions (free RNA) and used for northern blot analysis to monitor the tRNAThr $3^{\prime}$ half (length: 37 nucleotides). In $\mathbf{a}$ and $\mathbf{b}$ representative data of three independent experiments are shown. $\mathbf{c}$ Fractions from the polysome profiles of unstressed (no stress) or starved (stress) cells were also investigated for the presence of the YFP-tagged DHH1 (73 kDa) by western blot analysis. The location of molecular weight protein markers are indicated (see also Supplementary Figure 16). Western blots have been repeated twice. d Association of the tRNA ${ }^{\text {Thr }} 3^{\prime}$ half to ribosomes was analyzed employing in vitro filter binding assay using gradient-purified $80 \mathrm{~S}$ ribosomes isolated from starvation stressed or unstressed cells and $5^{\prime}\left[{ }^{32} \mathrm{P}\right]$-end labeled synthetic tRNA halves. The mean and standard deviation of four independent binding experiments are shown underneath the scan, whereas binding efficiency employing unstressed 80 S ribosomes was set to 1.00

the tRNA ${ }^{\text {Thr }}$ half-mediated translation stimulation can also be observed in other species. Therefore, we introduced the synthetic T. brucei tRNA ${ }^{\text {Thr }}$ half either into the halophilic archaeon Haloferax volcanii or the yeast S. cerevisiae. In both organisms we did observe an analogous stimulation in protein synthesis (Supplementary Figure 9a). Also mammalian protein synthesis is stimulated by this tRNA half as exemplified by HeLa extractbased in vitro translation reactions (Supplementary Figure 9b). While we do not have evidence that a similar endogenous tRNAfragment exists in $H$. volcanii, $S$. cerevisiae or human cells, the mere fact that the $T$. brucei $\mathrm{tRNA}^{\mathrm{Thr}}$ half functions in distantly related species argues for a highly conserved mode of action.

To gain first mechanistic insight into tRNA Thr $3^{\prime}$ half function, we tested whether this rancRNA stimulates translation by promoting mRNA binding to the ribosome. To this end T. brucei in vitro translation reactions were assembled, protein synthesis stopped after 5 or $20 \mathrm{~min}$ by the addition of cycloheximide and the ribosomes subsequently pelleted through a sucrose cushion. Northern blot analyses on the ribosome pellet and the corresponding supernatant fractions demonstrated enhanced levels of the highly abundant tubulin mRNA on ribosomes (between 1.3 and 3.8-fold) in the presence of the tRNA ${ }^{\text {Thr }} 3^{\prime}$ half (Fig. 5d). Concomitantly, tubulin mRNA levels decreased in the ribosome-free supernatants thus hinting at enhanced translation initiation in the presence of the tRNA half.

Depletion of the endogenous tRNA ${ }^{\text {Thr }}$ half eases stimulation. To study the effect of the endogenous tRNA ${ }^{\text {Thr }} 3^{\prime}$ half on protein synthesis we performed affinity purification using a biotinylated antisense DNA oligonucleotide. As input the size-selected small RNA pool (30-40 nucleotides) of $T$. brucei cells was utilized (Fig. 6a). Subsequently the affinity purified material, which is enriched in $\mathrm{tRNA}^{\mathrm{Thr}} 3^{\prime}$ half, and the flow through, which represents the small RNA pool depleted of this tRNA half (Fig. 6b), were tested in in vitro translation reactions. Addition of the affinity purified tRNA ${ }^{\text {Thr }}$ half to in vitro translation reactions showed a very mild stimulatory effect (Fig. 6c). The lack of significant translation stimulation under these conditions is due to the considerably low concentration of retrieved endogenous tRNA $^{\text {Thr }} 3^{\prime}$ half molecules $(\sim 1$ pmol per reaction as compared to 500 pmol in regular in vitro translation reactions; Supplementary Figure 10). However, when the endogenous pool of small RNAs depleted from the tRNA Thr $3^{\prime}$ half was used in in vitro translation assays we observed a marked inhibition of translation (Fig. 6c). This was solely due to the lack of the tRNA ${ }^{\text {Thr }} 3^{\prime}$ half as the control fraction (fraction III; - biot-ASO in Fig. 6c) did not show such an effect. These data suggest that in T. brucei cells the tRNA $^{\text {Thr }}$ half counteracts the inhibitory effects of other small RNAs, such as other tRNA-derived fragments that might be present in this size range, on protein biosynthesis. In vivo support for this interpretation comes from experiments introducing antisense oligonucleotides (ASO) targeting the endogenous tRNA ${ }^{\mathrm{Thr}}$ $3^{\prime}$ half. Electroporation of these ASO into T. brucei neutralizes the role of the endogenous tRNA ${ }^{\mathrm{Thr}}$ half resulting in a clear translation inhibition during stress recovery as measured in the metabolic labelling assay (Fig. 6d). 
a
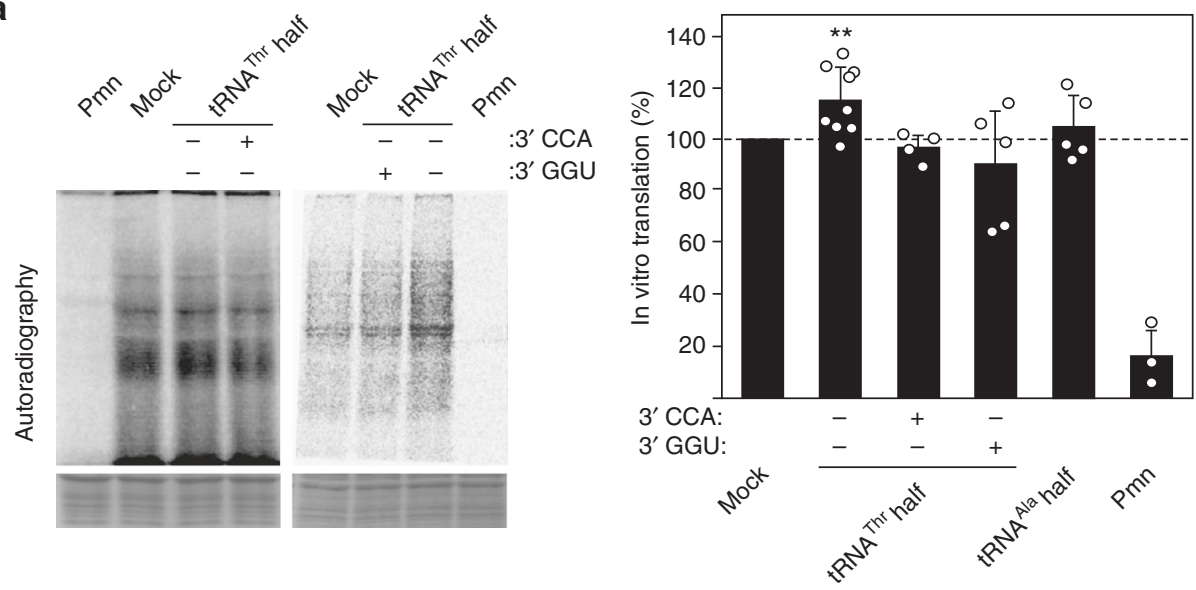

b

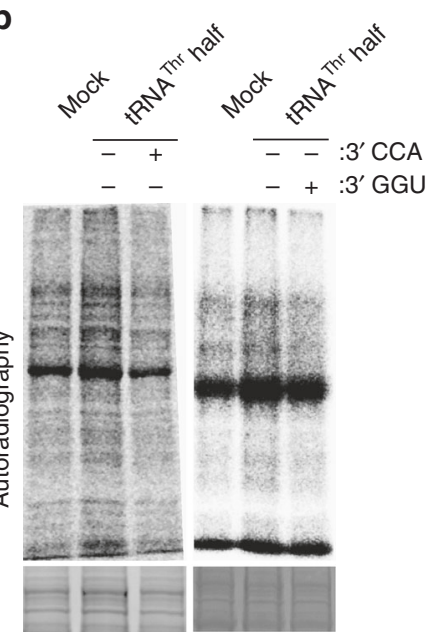

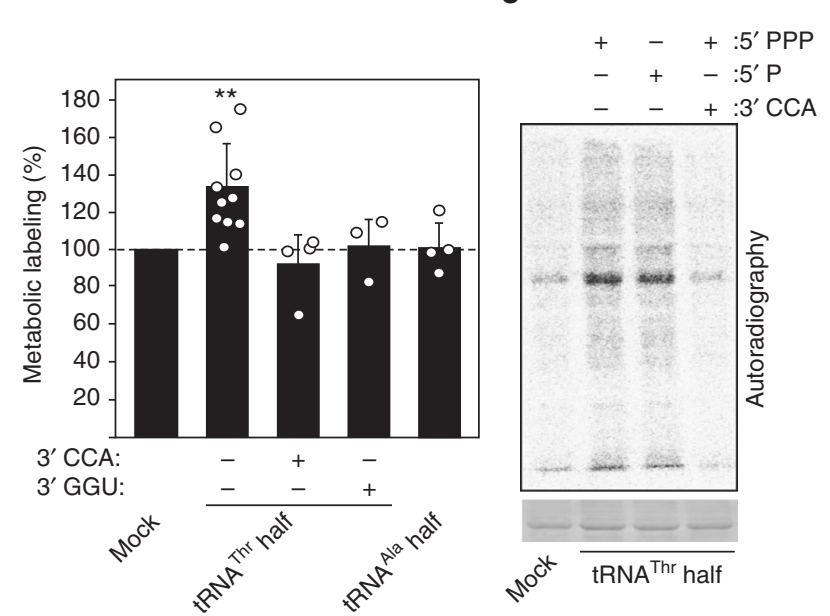

d

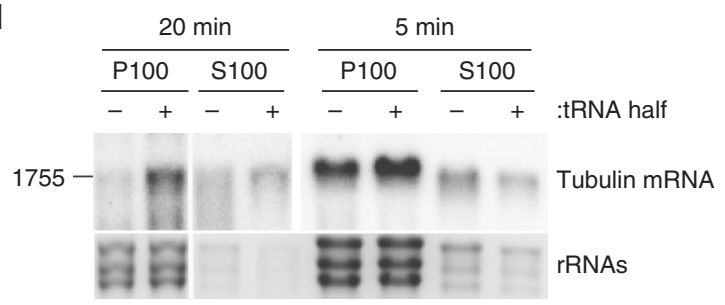

Fig. 5 The tRNA ${ }^{\text {Thr }} 3^{\prime}$-half stimulates translation in vitro and in vivo. a On the left, the autoradiographs of two representative SDS polyacrylamide gels of in vitro translation assays performed in the absence (mock) or in the presence of in vitro transcribed tRNA ${ }^{\text {Thr }} 3^{\prime}$ half, either containing a $3^{\prime}$-CCA or 3'-GGU end $(+)$ or lacking it $(-)$, are shown. The mean and standard deviations of four to nine independent in vitro translation experiments in the absence (mock) or presence of tRNA halves (either originating from tRNA ${ }^{\text {Thr }}$ of tRNA ${ }^{A l a}$ ) are shown on the right graph. Addition of the translation inhibitor puromycin $(\mathrm{Pmn})$ serves as specificity control for the assay $(n=3)$. $\mathbf{b}$ On the left, the autoradiograph of two representative gels of in vivo translation reactions performed in the absence (mock) or in the presence of electroporated tRNA Thr $3^{\prime}$ halves, either containing a 3'-CCA or 3'-GGU end (+) or lacking it (-), are shown. Quantification (mean and standard deviation) of three to ten independent metabolic labeling experiments in the absence (mock) or presence of introduced tRNA halves (either originating from tRNA ${ }^{\text {Thr }}$ of tRNA ${ }^{\text {Ala }}$ ) is shown on the right graph. c Autoradiograph of an in vivo translation assay using electroporated tRNA Thr $3^{\prime}$ halves containing different chemical groups at the $5^{\prime}$ end. A representative gel of in total four independent experiments is shown. 5'-PPP: 5' triphosphate; 5'-P: 5' monophosphate. 3'-CCA: indicates the presence or absence of a 3' CCA tail. Significance in $\mathbf{a}$ and $\mathbf{b}$ according to paired Student's $t$-test: ${ }^{\star \star} P \leq 0.01$. d Abundance of tubulin mRNA (1755 nucleotides; see Supplementary Figure 17a) associated with ribosomes (P100) during $T$. brucei in vitro translation reactions in the presence or absence of the tRNA Thr $3^{\prime}$ half was monitored by northern blot analysis $(n=2)$. S100 indicates the respective post-ribosomal supernatants. Reactions were stopped either after 5 or 20 min of incubation. In all figures either Coomassie stained protein gels or EtBr staining of RNA gels (bottom panels) serve as loading controls

\section{Discussion}

Kinetoplastids, including T. brucei, possess a very peculiar RNA biology. For example, most mitochondrial mRNAs are highly edited by insertions/deletions of uridines, all tRNAs need to be imported into mitochondria, certain tRNAs are posttranscriptionally processed by interdependent modification/ editing systems ${ }^{21}$, cytoplasmic ribosomes are composed of several distinct large ribosomal subunit rRNA fragments ${ }^{22}$, or polycistronic primary mRNA transcripts are processed into mature mRNAs via a process called trans-splicing (reviewed in ref. ${ }^{23}$ ). All these RNA particularities are orchestrated by dedicated processing/editing/transport machineries thus rendering them as 
a Endogenous tRNA ${ }^{\text {Thr }}$ half $\|$

\section{T. brucei small RNA pool I}

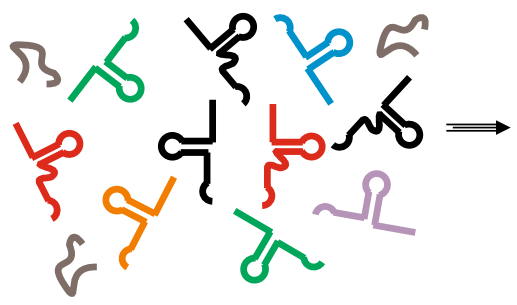
purification

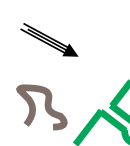

C

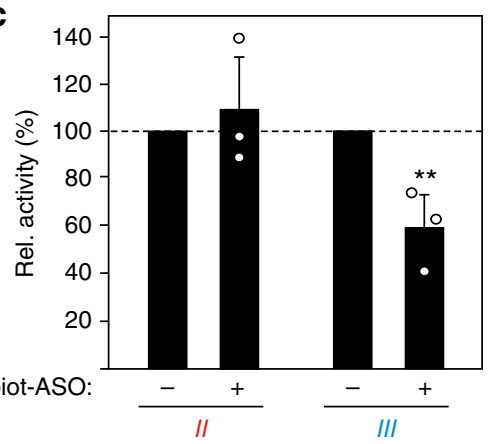

b

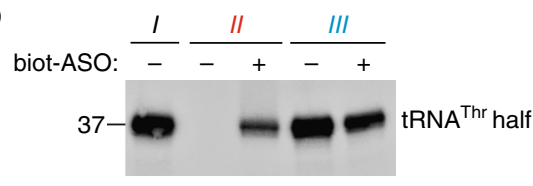

d
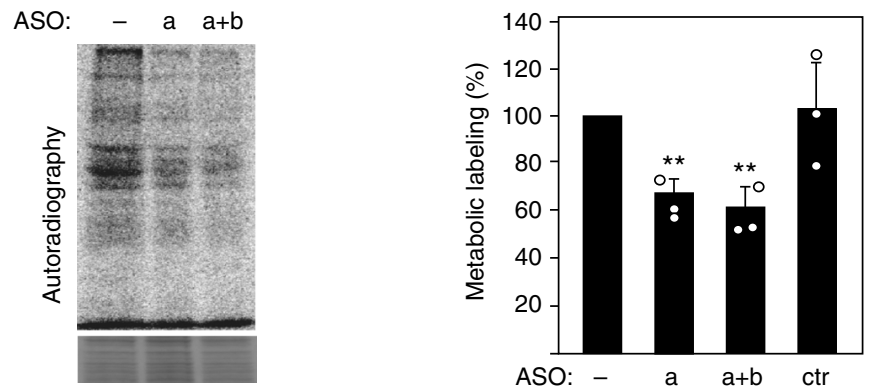

Fig. 6 Depletion of endogenous tRNAThr $3^{\prime}$ halves alleviates the stimulatory effects during translation. a Scheme of the strategy used for affinity purification of the endogenous tRNA ${ }^{\text {Thr }} 3^{\prime}$ half from the pool of small RNAs (size range between 30-40 nucleotides). As a control the same procedure was performed in the absence of a biotinylated antisense oligonucleotide (ASO). b Northern blot analysis of RNA extracted from the samples obtained after affinity purification showing the successful isolation of the tRNA ${ }^{\text {Thr }} 3^{\prime}$ half (see also Supplementary Figure 10) when using the biotinylated ASO (fraction II+) and its partial depletion from the corresponding flow through (compare fractions III, - and +ASO). A representative blot of in total two independent affinity purification experiments is shown. c Depletion of endogenous tRNA ${ }^{\text {Thr }} 3^{\prime}$ halves from the pool of small RNAs results in reduced in vitro translation activities. The effects of RNA fractions obtained after affinity purification were tested on in vitro translation. Quantification (mean and standard deviation) shows the average of three independent experiments. $\mathbf{d}$ Chemically modified ASO complementary to the tRNA ${ }^{\text {Thr }} 3^{\prime}$ half were electroporated into T. brucei cells and their effect on in vivo translation was investigated by metabolic labeling during stress recovery. The autoradiograph shows a representative SDS polyacrylamide gel in which metabolic labeling was performed in cells electroporated without an ASO (-) or cells electroporated with one (a) or two $(a+b)$ different ASO targeting endogenous tRNAThr $3^{\prime}$ halves. Coomassie staining of the gel (bottom panel) serve as loading control. Quantification of three independent metabolic labeling experiments is shown on the right. As specificity control metabolic labeling was performed also after electroporation of an analogous ASO without any sequence complementarity to the tRNA ${ }^{\text {Thr }} 3^{\prime}$ half (ctr). Significance according to paired Student's $t$-test: ${ }^{\star \star} P \leq 0.01$

potential targets for therapeutic interventions. We have recently identified the class of ribosome-associated small ncRNAs (rancRNAs) as a thus far unknown family of translation regulators ${ }^{9}$. RancRNAs directly associate with the translation machinery and due to their small size and immediate availability possess the potential of being first-wave regulators during stress encounters $^{8}$. To gain insight into T. brucei rancRNA biology we sequenced and analyzed a rancRNA library originating from cells grown to exponential or stationary phases (procyclic as well as bloodstream form) and from temperature-stressed or starved cells. It became evident that especially tRNA-derived reads increase significantly upon starvation and that most of them represent tRNA halves (Fig. 1a, b).

One of the most abundant tRNA-derived species originates from the $3^{\prime}$ half of $\mathrm{tRNA}{ }^{\text {Thr }}$ during nutritional stress and during the stationary phase in the procyclic form (Fig. 1d, Supplementary Figure 1, Supplementary Data 1). The production of tRNA halves by cleavage in or around the anticodon loop during various stress conditions has been observed before in different model systems including Trypanosomatids ${ }^{24}$, ciliates $^{25}$, and mammalian cells ${ }^{26-29}$. In the kinetoplast $T$. cruzi tRNA halves were also detected during unstressed conditions ${ }^{30}$ but became more abundant under nutritional stress ${ }^{24}$. While uncovering the physiological role of these tRNA fragments awaits further dedicated research, it could be shown that in T. cruzi these stress-induced tRNA halves accumulate in cytoplasmic granules. In subsequent studies, it was shown that a certain amount of these tRNA halves are secreted to the growth medium in extracellular vesicles 31,32 thereby potentially delivering regulatory ncRNA molecules to other parasites as well as to mammalian cells. A similar role for 
exosome-packed small RNA molecules, including tRNA halves, has been recently suggested in protozoan parasites of the genus Leishmania $^{33}$. Analogous insight into the tdR RNome and its putative function in the closely related parasite T. brucei is largely missing ${ }^{34}$. In variance to the tRNA halves pool in T. cruzi, which seems to be dominated by halves originating from only a few tRNA isoacceptors ${ }^{24,30}$, the T. brucei tRNA halves population is much more diverse (Supplementary Figure 1, Supplementary Data 1).

While in most reported cases the biological role and the cellular target of the sequenced tRNA half molecules remained elusive, some studies clearly demonstrated a function relevant for stress response. In human cells it was shown that the stress-induced tRNA Ala $5^{\prime}$ half inhibited protein synthesis by sequestering certain translation initiation factors and promotes stress granule formation ${ }^{13,28}$. The tRNA ${ }^{\text {Thr }} 3^{\prime}$ half identified here functions in a markedly different manner. It is produced during starvation conditions or when procyclic T. brucei cells enter stationary phase and it binds to ribosomes and polysomes (Fig. 4). However, instead of inhibiting the translation machinery, as it has been shown for other rancRNAs ${ }^{6-8}$, this ribosome-bound RNA stimulates protein biosynthesis (Fig. 5). Particularly after prolonged starvation, which leads to a complete loss of cell motility, the tRNA $^{\text {Thr }} 3^{\prime}$ half is produced, associates with ribosomes and stimulates protein synthesis during the stress recovery phase. Blocking of endogenous tRNA ${ }^{\text {Thr }}$ halves via an antisense oligonucleotide (ASO) approach or depleting the $\mathrm{RNA}^{\mathrm{Thr}}$ halves by affinity purification eases this stimulatory effect on protein biosynthesis in vivo and in vitro (Fig. 6). While the tRNA ${ }^{\text {Thr }}$ half is special in the sense that it is the only $3^{\prime}$ half identified to robustly associate with ribosomes (Fig. 1d), structurally it does not show any obvious peculiarities compared to other identified tRNAderived fragments. The aforementioned human tRNA ${ }^{\text {Ala }} 5^{\prime}$ half, demonstrated to inhibit translation initiation and promote stress granule formation, was shown to form G-quadruplexes as prerequisite for its biological function ${ }^{35}$. The T. brucei tRNA ${ }^{\text {Thr }} 3^{\prime}$ half however does not seem to adopt G-quadruplex structures (Supplementary Figure 11) thus hinting at a different mode of action.

Interestingly in the bloodstream form of $T$. brucei, the predominant form of the parasite within the mammalian host, this tRNA half is present in easily detectable amounts throughout all growth phases or stress situations (Fig. 2). This suggests that during this life stage the metabolism of $T$. brucei can more strongly benefit from the presence of this rancRNA. It is known that the doubling time of $T$. brucei bloodstream forms is significantly shorter compared to the insect form ${ }^{36}$, which could be in part related to the stimulatory effect on metabolism of the tRNA ${ }^{\text {Thr }} 3^{\prime}$ half. In this context it would be of great interest to investigate the situation in other life stages, namely in the nondividing forms stumpy and metacyclic trypanosomes.

How can a rancRNA stimulate the ribosome during protein production from a mechanistic point of view? When investigating a specific endogenous mRNA we demonstrated enhanced association of the tubulin $\mathrm{mRNA}$ with ribosomes in the presence of the tRNA ${ }^{\text {Thr }} 3^{\prime}$ half (Fig. 5d). These findings are compatible with the view that the tRNA half stimulates translation by promoting the initiation phase in T. brucei. In order for the tRNA Thr $3^{\prime}$ half to fulfill this role in vitro and in vivo, the $3^{\prime}$ CCA end needs to be removed (Fig. 5a, b). We have shown that almost all tRNAs rapidly lose their CCA end upon starvation (Supplementary Figure 1a). In the presence of $3^{\prime}$ extensions on the half, CCA or the artificially added GGU, the translation stimulatory effect is lost. This opens the possibility for a straightforward regulation of the tRNA ${ }^{\text {Thr }} 3^{\prime}$ half activity in vivo by modulating the extent of $3^{\prime}$ CCA tail addition/removal. Comparing northern blot signals for the $\mathrm{tRNA}^{\mathrm{Thr}} 3^{\prime}$ half to synthetic standards revealed about 2500 molecules per stressed cell. Therefore the tRNA ${ }^{\text {Thr }} 3^{\prime}$ half is approximately two orders of magnitude less abundant than the expected ribosome pool in T. brucei. However, one can envision a role of this tRNA half acting in a turnover mode. Our affinity purification experiments demonstrated that depletion of the tRNA $^{\text {Thr }}$ half from the pool of small RNAs in the size range between 30-40 nucleotides actually inhibits global translation (Fig. 6c). It is therefore conceivable that the tRNA ${ }^{\text {Thr }} 3^{\prime}$ half counteracts any inhibitory small RNA in this size range (including other potential tRNA-derived RNAs) present in a stressed cell. We have shown before in S. cerevisiae and H. volcanii that rancRNAs can have global inhibitory effects on protein production in vivo despite the fact that they are less abundant than the ribosome pool ${ }^{6,8}$. Thus even though we do not have uncovered the complete molecular mechanism used by the tRNA $^{\text {Thr }} 3^{\prime}$ half to boost translation in T. brucei during stress recovery, our data are compatible with a stimulatory role during mRNA loading (Fig. 5d). In this scenario, the tRNA ${ }^{\text {Thr }}$ halfoccupied ribosomes (a complex which accumulates during nutrient deprivation (Figs. $2 \mathrm{a}-\mathrm{c}$ and $4 \mathrm{~b}$ )) are more efficient recommencing translation, once the parasite encounters more favorable environmental conditions. Based on the presented SDS gels (Fig. $5 \mathrm{a}-\mathrm{c}$ ), the tRNA ${ }^{\text {Thr }}$ half appears to affect global translation rather than specific mRNAs.

In human cells stress-induced tRNA halves are known to be produced by angiogenin, an RNase A-type enzyme that cleaves tRNAs in the anticodon loop ${ }^{25,28}$. T. brucei does not possess an angiogenin homolog, implying an alternative tRNA half biogenesis pathway in the parasite. In humans and plants it has been reported that tRNA-derived RNA fragments (tdRs) can also be produced by Dicer, a central endonuclease of the si/miRNA machinery ${ }^{37,38}$. Since T. brucei does possess the siRNA pathway albeit lacking miRNAs, we investigated whether the Dicer homologs might be involved in processing of the tRNA ${ }^{\text {Thr }} 3^{\prime}$ half. Utilizing RNAi against the two dicer-like proteins (TbDCL1 and TbDCL2) we could exclude these nucleases as being involved in tRNA cleavage in T. brucei (Supplementary Figure 12). In yeast Rny1, a member of the RNase T2 family, has been shown to cleave tRNAs in the anticodon loop during oxidative stress thus producing half molecules ${ }^{39}$. However, no Rnyl homolog has been identified in the genomes of T. brucei or its close relatives. It is remarkable that the involvement of tdRs in regulating cellular processes is evolutionarily so conserved (it can be observed in all domains of life), yet their biogenesis seems to involve a big variety of diverse enzymes. It therefore appears that in Kinetoplastids, a completely different tRNA processing machinery is at work which awaits to be uncovered.

The tRNA Thr $3^{\prime}$ half described herein is the latest addition of functional tdRs reported in recent years. The class of tdRs, which includes tRNA halves as well as also shorter fragments of 14-26 nucleotides, was initially described in cells and organisms exposed to challenging growth conditions in all three domains of life (reviewed in refs. ${ }^{40,41}$ ). Subsequent studies revealed tdRs also during normal conditions suggesting possible house-keeping functions (ref. ${ }^{42}$ and references therein). Certain tdRs have been recognized as pivotal regulators of cell metabolism, particularly during cellular stress and disease (reviewed in refs. ${ }^{41,43}$ ). Unlike other small ncRNA regulators (such as miRNA, siRNAs or piRNAs) tdRs are a structurally and functionally highly multifaceted class of ncRNAs ${ }^{40}$. The so far identified biological roles of tdRs include regulation of transcription, translation, stress granule formation, apoptosis, cell proliferation, RNAi, vesicle-mediated intercellular communication, intergenerational inheritance, and retrotransposition (reviewed in ref. ${ }^{40}$ ). Very recently a 22 nucleotide long tdR has been identified to regulate ribosome 
biogenesis in human cells by controlling translation of crucial ribosomal proteins ${ }^{44}$. RNAi against this tdR resulted in impaired cell viability and increased apoptosis in human cancer models. In most of the reported cases on tdR function the tRNA fragment seems to inhibit a cellular process. The T. brucei tRNA Thr $3^{\prime}$ half reported here is one of the few examples in which a tdR stimulates a cellular function, such as translation during stress recovery. This further diversifies the regulatory potential of tdRs as compared to other small ncRNA regulators. Therefore we cannot exclude the possibility that the T. brucei $\mathrm{tRNA}^{\mathrm{Thr}} 3^{\prime}$ half has additional biological roles in the parasite beyond translation control. It is astounding that the "precursor" molecule of tdRs, genuine tRNA that is, has basically one major cellular role as substrate for the protein synthesis machinery, while processing products thereof are functionally so heterogeneous. Thus posttranscriptional cleavage events can generate novel regulatory molecules thereby further increasing the complexity of cellular RNomes in general and expanding tRNA biology in particular.

\section{Methods}

Strains and growth conditions. Trypanosoma brucei procyclic stage (PCF) 427, 29-13 or bloodstream forms New York single markers (NYSM) ${ }^{45}$ cell lines were used in all experiments. Procyclic stage cells 427 and $29-13$ were grown at $27^{\circ} \mathrm{C}$ in SDM-79 media supplemented with 5 or $10 \%$ fetal calf serum (FCS), respectively ${ }^{46}$. Bloodstream forms (BSF) were cultured in HMI-9 medium containing $10 \%$ FCS at $37^{\circ} \mathrm{C} / 5 \% \mathrm{CO}_{2}\left(\right.$ ref. $\left.{ }^{47}\right)$. Cultures were harvested in the exponential growth phase at densities lower than $2 \times 10^{7}$ cells $/ \mathrm{ml}$ for PCF and $10^{6}$ cells $/ \mathrm{ml}$ for BSF. For stationary phase procyclic cells were harvested at a density of $6-7 \times 10^{7} \mathrm{cells} / \mathrm{ml}$. For heat shock, exponentially growing cells were incubated $30 \mathrm{~min}$ in $41^{\circ} \mathrm{C}$ prewarmed medium; cold shock was applied to PCF cells by incubating them for $30 \mathrm{~min}$ in $13{ }^{\circ} \mathrm{C}$ media; oxidative stress: media containing $125 \mu \mathrm{M}$ of oxygen peroxide $\left(\mathrm{H}_{2} \mathrm{O}_{2}\right)$ for $1 \mathrm{~h}$. Unless stated otherwise, nutritional stress was applied to PCF cells by incubating them for $2 \mathrm{~h}$ in $1 \mathrm{x}$ PBS (phosphate buffered saline) at $27^{\circ} \mathrm{C}$. Nutritional stress of BSF involved incubation for $1 \mathrm{~h}$ in $1 \mathrm{x}$ PBS at $37^{\circ} \mathrm{C}$. A cell line expressing an endogenous copy of DHH1 N-terminally tagged (eYFP) was constructed using a plasmid kindly provided by Kramer and Carrington ${ }^{15}$. Transfection, cloning and selection of transgenic 427 procyclic cells were done as described ${ }^{48}$.

\section{RancRNA library preparation and bioinformatics analyses. Ribosome-} associated small RNAs were isolated as described ${ }^{49}$. The cDNA library was prepared using the TruSeq Small RNA Library Prep kit (Illumina) and sequenced using the Illumina HiSeq 2000 platform. Bioinformatics analysis was performed as described by Luidalepp et $\mathrm{al}^{50}$ with the exception that four mismatches were allowed. Overlapping read pairs were joined using Pandase ${ }^{51}$. Next, reads were mapped to the T. brucei TREU927 reference genome obtained from TriTrypDB ${ }^{52}$ using STAR ${ }^{53}$. The genome annotation in version 32 of TriTrypDB was complemented with tRNA gene prediction using tRNAscan-SE ${ }^{54}$ and transcript features were extended by 50 nucleotides up and downstream to include tRNA precursor regions. Subsequently, reads mapping within annotated transcripts were extracted and putative processing products were identified with a modified version of the APART pipeline ${ }^{10}$. In particular, for the identification of RNA processing events, read blocks as defined using the blockbuster algorithm ${ }^{55}$ were used instead of contigs composed of overlapping reads. The normalization of expression levels across samples was performed using the Bioconductor and edgeR package ${ }^{56}$. The statistical analysis was performed in the R environment. All sequencing reads were submitted to the European Nucleotide Archive (ENA) and can be accessed with the number PRJEB24915.

Electroporation of procyclic T. brucei cells. Exponential growing 427 cells $(4.5 \times$ $\left.10^{7}\right)$ were harvested by centrifugation $\left(1400 \times g\right.$ for $10 \mathrm{~min}$ at $\left.4^{\circ} \mathrm{C}\right)$ and resuspended in $1 \mathrm{ml}$ of ice cold 1x Cytomix (25 mM HEPES/KOH pH 7.6, $10 \mathrm{mM}$ $\mathrm{K}_{2} \mathrm{HPO}_{4}, 120 \mathrm{mM} \mathrm{KCl}, 0.15 \mathrm{mM} \mathrm{CaCl}_{2}, 5 \mathrm{mM} \mathrm{MgCl}, 2 \mathrm{mM}$ EDTA). Cells were washed with $1 \mathrm{ml} 1 \mathrm{x}$ Cytomix, resuspended in $190 \mu \mathrm{l} 1 \mathrm{x}$ Cytomix and mixed with $500 \mathrm{pmol}$ of in vitro transcribed tRNA half in 1x annealing buffer $(10 \mathrm{mM}$ Tris$\mathrm{HCl}$; $\mathrm{pH} 7.6,80 \mathrm{mM} \mathrm{MgCl}_{2}$ ) to a final volume of $200 \mu$ l. The mixture was electroporated twice using a Bio-Rad gene pulser II $(1.2 \mathrm{kV}, 25 \mu \mathrm{F}$, and $0 \mathrm{Ohm})$ in a $4 \mathrm{~mm}$ electroporation cuvette (EP-104, Cell Projects Ltd.). Finally, the procyclic $T$. brucei cells were resuspended with $1 \mathrm{ml}$ of SDM-79 (5\% FCS) and transferred into pre-warmed $3 \mathrm{ml}$ medium for a $2 \mathrm{~h}$ recovery at $27^{\circ} \mathrm{C}$. The following RNA strands were produced by in vitro transcription using T7 RNA polymerase ${ }^{57,58}$ and subsequently introduced with this approach into T. brucei: Thr_(AGU)- $3^{\prime}$-half + CCA: 5' AAGACGGAGGUCGGGGGUUCGAUCCCCCCAGUGGCCUCCA 3', Thr_(AGU)-3'-half-CCA: 5' AAGACGGAGGUCGGGGGUUCGAUCCCCCCA GUGGCCU 3', Thr_(AGU)-3'half + GGU: 5' AAGACGGAGGUCGGGGGUUC
GAUCCCCCCAGUGGCCUGGU 3', Thr_(AGU)-5'-half: 5' GGCCGCUUAGCU CAAUGGCAGAGCGCCGUCCUAGU $3^{\prime}$. The tRNA ${ }^{\text {Ala }} 5^{\prime}$ half used was a synthetic oligonucleotide (Microsynth) with the sequence Ala_(CGA)-5'-half: 5' GGGGAUGUAGCUCAGAUGGUAGAGCGCCCGCUUAGC 3'.

Metabolic labeling. Translation activity in T. brucei was monitored by metabolic labeling. $4.5 \times 10^{7}$ procyclic cells were electroporated with the tRNA halves $(500 \mathrm{pmol})$ as described above, allowed to recover for $2 \mathrm{~h}$ under normal growth conditions and finally stressed by incubation in $1 \mathrm{x}$ PBS. After $2 \mathrm{~h}$ of nutritional stress, the cells were again harvested (see above) and resuspended in $750 \mu \mathrm{l}$ prewarmed media. $1 / 3$ or the cells were used for RNA extraction and subsequent detection of the electroporated tRNA halves by northern blot analysis. The remaining $2 / 3$ of the cells were mixed with $250 \mu$ SDM-79 (5\% FCS) containing 2 $\mu \mathrm{l}$ of L-35 ${ }^{35}$-methionine $(10 \mu \mathrm{Ci} / \mu$, Hartmann Analytic) and incubated for $60 \mathrm{~min}$ at $27^{\circ} \mathrm{C}$. After metabolic labeling the cells were harvested, resuspended in $1 \mathrm{x}$ Laemmli buffer and proteins were separated by $10 \%$ SDS-PAGE. Radiolabeled methionine incorporation was measured by phosphorimaging. Metabolic labeling in $H$. volcanii and S. cerevisiae was performed as described previously ${ }^{6,8}$.

Inactivation of tRNA ${ }^{\text {Thr }} \mathbf{3}^{\prime}$ half by ASOs. To block the endogenous tRNA ${ }^{\text {Thr }} 3^{\prime}$ half, modified ASOs were used (ASO_a: $\mathrm{mG}^{*} \mathrm{~mA}^{*}$ $m A^{\star} m C^{\star} m C^{\star} C^{\star} C^{\star} C^{\star} C^{\star} G^{\star} A^{\star} C^{\star} C^{\star} T^{\star} C^{\star} C^{\star} m G^{\star} m T^{\star} m C^{\star} m T^{\star} m T$ and ASO_b

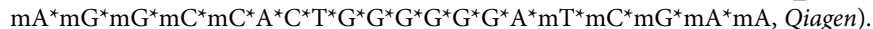
As specificity control an analogous ASO strand with a completely unrelated sequence was used (ASO_ctr: $\mathrm{mG}^{*} \mathrm{mU}^{*} \mathrm{~mA}^{*} \mathrm{mU}^{*} \mathrm{mU}^{*} \mathrm{~T}^{\star} \mathrm{A}^{*}$ -

$C^{*} A^{*} A^{*} T^{*} T^{*} G^{*} A^{*} C^{\star} m G^{*} m U^{*} m A^{*} m U^{*} m A$. All ASOs were designed as RNA/ DNA/RNA chimeras with a phosphorothioate backbone (asterisks). The ten central deoxyribonucleotides are flanked by five 2'-O-methyl modified ribonucleotides. $500 \mathrm{pmol}$ of the ASO were electroporated into $4.5 \times 10^{7}$ cells. After two hours of recovery in normal media nutritional stress was applied for four hours and global translation was assessed during a two-hour recovery period by metabolic labeling as described.

Cell extract preparation. Cells grown under different conditions were harvested (see above) and the cell pellets $\left(1-3 \times 10^{9}\right.$ cells) resuspended in $500 \mu \mathrm{l}$ ribosome buffer A (120 mM KCl, $20 \mathrm{mM}$ Tris/HCl pH 7.6, $2 \mathrm{mM} \mathrm{MgCl} 2,1 \mathrm{mM}$ DTT) containing $20 \mathrm{mM}$ ribonucleoside vanadyl complex (RVC, Bioconcept) and $2.5 \mu \mathrm{l}$ of RiboLock (40 U/ $\mu$ l, Thermo Scientific) and flash frozen. Samples were passed 10 times through a $25 \mathrm{G}$ needle and 10 times through a $27 \mathrm{G}$ needle and extracts were cleared by centrifugation. Cell extracts were aliquoted, snap frozen and stored at $-80^{\circ} \mathrm{C}$ until use

T. brucei in vitro translation. One in vitro translation reaction with a total volume of $30 \mu \mathrm{l}$ is composed of $6 \mu \mathrm{l}$ "translation mix" and $24 \mu \mathrm{l}$ "sample mix". The $6 \mu \mathrm{l}$ translation mix contained $3 \mu \mathrm{l} 10 \mathrm{x}$ translation cocktail ( $100 \mathrm{mM} \mathrm{Hepes} / \mathrm{KOH} \mathrm{pH}$ $7.4,15 \mathrm{mM} \mathrm{Mg}(\mathrm{OAc})_{2}, 750 \mathrm{mM}$ KOAc, $4 \mathrm{mM}$ GTP, $10 \mathrm{mM}$ ATP, $500 \mu \mathrm{M}$ of each amino acid except methionine), $0.5 \mu \mathrm{l}$ of $\mathrm{Mg}(\mathrm{OAc})_{2}(100 \mathrm{mM}), 0.5 \mu \mathrm{l}$ of creatine phosphokinase $(10 \mathrm{mg} / \mathrm{ml}$, Roche), $1 \mu \mathrm{l}$ of creatine phosphate $(0.6 \mathrm{M})$ and $1 \mu \mathrm{l}$ of L${ }^{35} \mathrm{~S}$-methionine $(10 \mu \mathrm{Ci} / \mu \mathrm{l})$. The $24 \mu \mathrm{l}$ sample mix was composed of $3 \mu \mathrm{l} \mathrm{DMSO}$, $7 \mu \mathrm{l}$ T. brucei cell extract (extract prepared as described above and this volume corresponds to $2-4 \times 10^{7}$ cell equivalents) containing $20 \mathrm{mM} \mathrm{RVC}, 7.5 \mu \mathrm{l}$ ribosome buffer B (120 mM KCl, $20 \mathrm{mM}$ Tris/HCl pH 7.6, $\left.8 \mathrm{mM} \mathrm{MgCl}_{2}\right), 500$ pmol tRNA halves in annealing buffer $(10 \mathrm{mM}$ Tris/ $\mathrm{HCl} \mathrm{pH} 7.6$ and $20 \mathrm{mM} \mathrm{NaCl})$. The reaction was started by combining the translation mix with the sample mix and proceeded for $20 \mathrm{~min}$ at $27^{\circ} \mathrm{C}$. The reaction was stopped by addition of $1 \mathrm{x}$ Laemmli buffer and incubation at $95^{\circ} \mathrm{C}$ for $2 \mathrm{~min}$. Proteins were subsequently separated on a $10 \%$ SDS-PAGE gel and methionine incorporation was monitored by phosphorimaging. For testing the tRNA ${ }^{\text {Asp }} 3^{\prime}$ half (anticodon GUC) during in vitro translation, the in vitro transcribed RNA strand 5' CACGCGGGUGACCCGGGU UCAAUUCCCGGCCGGGAAGCCA $3^{\prime}$ was used as above. To test the effect of endogenous tRNA ${ }^{\text {Thr }} 3^{\prime}$ half $5 \mu \mathrm{l}(\sim 1 \mathrm{pmol})$ of affinity purified samples (or the equivalent volume of the corresponding flow through) were used with $3.5 \mu \mathrm{l}$ cell extract prepared with RVC, $2.5 \mu$ ribosome buffer B in a total volume of $10 \mu \mathrm{l}$. Subsequently $3 \mu$ of translation mix was added. The reaction was incubated and stopped as described above.

To assess the mRNA association to T. brucei ribosome, the equivalent to four in vitro translation reactions (using cold L-methionine) were run as described above and stopped after 5 or $20 \mathrm{~min}$ by the addition of cycloheximide (final concentration $100 \mu \mathrm{g} / \mathrm{ml}$ ). Samples were loaded onto $800 \mu \mathrm{l}$ of a $1.1 \mathrm{M}$ sucrose cushion prepared in ribosome buffer A containing $1 \mathrm{mM} \mathrm{DTT}$ and $100 \mu \mathrm{g} / \mathrm{ml}$ cycloheximide. After centrifugation $\left(2.5 \mathrm{~h}\right.$ at $\left.200,000 \times g, 4^{\circ} \mathrm{C}\right)$ the supernatant (S100) was recovered, 2.5 vol. $100 \%$ ethanol was added and incubated overnight at $-20^{\circ} \mathrm{C}$. Samples were centrifuged $\left(16,000 \times g, 45 \mathrm{~min}, 4^{\circ} \mathrm{C}\right)$, the pellets resuspended in $1 \mathrm{ml}$ of trizol and RNA was extracted following the manufacturer's instructions. RNA was also extracted from the pellet fraction (P100) of the $200,000 \times g$ centrifugation step (see above) using trizol and used for mRNA northern blotting (see below). 
Affinity purification of tRNA ${ }^{\text {Thr }} \mathbf{3}^{\prime}$ half. To affinity purify the endogenous tRNA $^{\text {Thr }}$ half the cell lysates obtained from nutritionally stressed cells were first incubated for $1 \mathrm{~h}$ at room temperature prior to total RNA isolation. Hybridization to a complementary DNA strand was done by incubating $1 \mu \mathrm{l}(100 \mathrm{pmol})$ of a $3^{\prime}$ end-biotinylated antisense DNA oligo (biot-ASO) with $5 \mu \mathrm{g}$ of size-selected (30-40 nt) total RNA in $100 \mu \mathrm{l}$ of $5 \mathrm{x}$ SSC buffer $(750 \mathrm{mM} \mathrm{NaCl}, 75 \mathrm{mM}$ trisodium citrate). The sample was denatured for $3 \mathrm{~min}$ at $90^{\circ} \mathrm{C}$ followed by hybridization for $10 \mathrm{~min}$ at $65^{\circ} \mathrm{C}$. The RNA-DNA hybrid was immobilized onto pre-washed Streptavidin magnetics beads ( $25 \mu \mathrm{l}$, Roche diagnostics) and incubated for $30 \mathrm{~min}$ at room temperature with rotation. The supernatant containing the unbound RNA pool (flow through) was removed and stored for future use. Beads were washed once with $50 \mu \mathrm{l}$ of $1 \times$ SSC buffer and 3 times with $50 \mu$ of $0.1 \times$ SSC buffer. The tRNA ${ }^{\text {Thr }}$ half was eluted by heating the beads in $100 \mu$ of water at $75^{\circ} \mathrm{C}$ for $3 \mathrm{~min}$. Contaminating biot-ASO were removed by DNase I treatment (Thermo Scientific). The affinity purified tRNA half was extracted by using Roti ${ }^{\oplus}$-Aqua-P/C/I (Roth). Finally, the RNA of the flow through and the affinity purified tRNA half were precipitated with 2.5 volumes of $100 \% \mathrm{EtOH}$ at $-20^{\circ} \mathrm{C}$ overnight. The samples were washed with $70 \% \mathrm{EtOH}$ and resuspended in $15 \mu \mathrm{l}$ water. To verify the quality of the affinity purification procedure $200 \mathrm{ng}$ of RNA was loaded onto a denaturing $8 \%$ polyacrylamide gel followed by northern blot analysis. The sequence of the complementary DNA oligonucleotide (biot-ASO) used for affinity purification was 5' AAGCCACTGGGGGGATCGAACCCCCGACCTCCGTCTTACTAGGACG GCGCTCTGCCATTGAGCTAAGCGGCCAAA 3' (Microsynth). The 3' AAA overhang was added for better binding to the beads. As control, the entire affinity purification procedure was performed in the absence of biot-ASO as well.

Polysome profiling. For polysome profiling, cell extracts were prepared as previously described without the addition of RVC from exponentially growing or nutritionally stressed cells. $50-100 \mathrm{OD}_{260}$ of cell extract was layered on top of a $10-40 \%(\mathrm{w} / \mathrm{v})$ sucrose gradient prepared in ribosome buffer A in SW 32Ti tubes (Beckman Polyallomer Centrifuge tubes $25 \times 89 \mathrm{~mm}$ ). The gradients were centrifuged in a Beckman SW $32 \mathrm{Ti}$ rotor $\left(6 \mathrm{~h}\right.$ at $25,000 \mathrm{rpm}$ at $\left.4{ }^{\circ} \mathrm{C}\right)$. Gradients were pumped out and fractions were collected every $16 \mathrm{~s}$ while continuously monitoring the absorbance at $260 \mathrm{~nm}$. For downstream northern blot analyses the desired fractions were pooled and precipitated with EtOH before RNA extraction with $1 \mathrm{ml}$ of TRI Reagent (Zymo Research). For 80S ribosome preparation, the fractions containing monosomes were pooled into a Beckman Optiseal Polyallomer tubes (volume $32.4 \mathrm{ml}$ ) and filled up with $1 \mathrm{x}$ ribosome buffer A. The ribosomes were pelleted by ultracentrifugation at $33,000 \mathrm{rpm}(100,000 \times g)$ for $17 \mathrm{~h}$ at $4{ }^{\circ} \mathrm{C}$ (rotor type $60 \mathrm{Ti}$, Beckman). After centrifugation the pellet was resuspended in $200 \mu \mathrm{l}$ ribosome buffer $\mathrm{A}$. The concentration of ribosomes was determined by the absorption at $260 \mathrm{~nm}\left(1 \mathrm{~A}_{260}=18 \mathrm{pmol} 80 \mathrm{~S}\right)$.

Northern blot analyses. For northern blotting, 3-40 $\mu$ g total RNA extracted with TRI Reagent (Zymo Research) according to the manufacturer's protocol was complemented with 1 volume of 2x RNA loading dye and separated on an $8 \%$ denaturing polyacrylamide gel (7M Urea, in 1x TBE buffer). The gel was subsequently electroblotted onto a nylon membrane (Amersham Hybond $\mathrm{N}^{+}, G E$ Healthcare) as described ${ }^{7}$. See Supplementary Methods for a full list of DNA oligonucleotides used.

For tubulin mRNA northern blot analyses 1.6-3.1 $\mu \mathrm{g}$ RNA of the S100 and 4.4-6.0 $\mu$ g RNA P100 fractions (see in vitro translation procedure above) were run on a $1 \%$ agarose gel in $20 \mathrm{mM}$ MOPS buffer ( $\mathrm{pH}$ 7.0) containing $1.5 \%$ formaldehyde. Subsequently the RNA was blotted onto a nylon membrane (Amersham Hybond $\mathrm{N}^{+}$, GE Healthcare) by passive transfer. DNA probes were prepared from gel-purified PCR products of the tubulin gene and radioactively labelled by using the Prime-a-Gene labelling protocol (Promega). $2.5 \mu$ of a mixture of random hexamers $(100 \mu \mathrm{M}$; Thermo $)$ and $5 \mathrm{ng}$ of PCR product in a total volume of $17.5 \mu \mathrm{l}$ were heated to $95^{\circ} \mathrm{C}$ for five minutes to dissociate the dsDNA. After reanneal the random hexamer primers were extended by $1.5 \mu$ l of Klenow polymerase $(3 \mathrm{U})$ by the addition of $2.5 \mu \mathrm{l}$ Klenow buffer, $1 \mu \mathrm{l}$ of dNTPs $(20 \mu \mathrm{M}$ final concentration dATP, dTTP, dGTP), $2.5 \mu \mathrm{l}$ of [ $\alpha^{-32}{ }^{32}$ ]CTP for $1 \mathrm{~h}$ at $37^{\circ} \mathrm{C}$. The reaction was stopped by adding $2 \mu \mathrm{l}$ of $0.5 \mathrm{M}$ EDTA and $70 \mu \mathrm{l} \mathrm{H}_{2} \mathrm{O}$. The northern blot probe was heated to $95^{\circ} \mathrm{C}$ for five minutes and subsequently added to the prehybridized membrane. See Supplementary Figures 13-17 for uncropped blots and full-length gels.

Western blot analyses. Fractions (16s) were collected from a polysome profiling experiment of either exponential or PBS stressed DHH1-YFP tagged cell lysate (60 $\mathrm{OD}_{260}$ cell extract per gradient). Ten microlitres of every third fraction was mixed with $2 \mathrm{x}$ Laemmli buffer, denatured at $95^{\circ} \mathrm{C}$ for 2 min, loaded on a $10 \%$ SDS-PAGE gel, and run for $1 \mathrm{~h}$ at $160 \mathrm{~V}$. The gel was transferred onto a nitrocellulose membrane (Amersham Biosciences) and blocked for $1 \mathrm{~h}$ in $1 \mathrm{x}$ PBS containing $0.1 \%$ Tween-20 in 5\% nonfat dry milk. The membranes were incubated with mouse anti-GFP antibody (1:1000, Roche; cat. number: 11814460001$)$ at $4{ }^{\circ} \mathrm{C}$ overnight. After washing $(3 \times 10 \mathrm{~min}$ each with $1 \mathrm{x}$ PBS, $0.1 \%$ Tween-20) horseradish peroxidase conjugated secondary antibodies were added for $1 \mathrm{~h}$ at room temperature $(1: 3000 ;$ Roche $)$. The membranes were washed as before and results were visualized using an enhanced chemiluminescence SuperSignal West Femto Maximum Sensitivity Substrate (ThermoFisher Scientific).

In vitro binding studies. Binding studies of tRNA ${ }^{\text {Thr }} 3^{\prime}$ half to ribosomal particles purified from stressed or unstressed cells (as described above) were performed using a dot blot-filtering approach. For the filter binding assay $5 \mathrm{pmol}$ of $T$. brucei $80 \mathrm{~S}$ ribosomes were incubated with $1 \mu \mathrm{l}$ of $5^{\prime}-\left[{ }^{32} \mathrm{P}\right]$-end-labeled $\mathrm{tRNA} \mathrm{A}^{\mathrm{Thr}}$ half $(4 \mathrm{pmol} / \mu \mathrm{l})$ in $25 \mu \mathrm{l}$ ribosome buffer B for $30 \mathrm{~min}$ at $27^{\circ} \mathrm{C}$. After incubation the reactions were filtered through a nitrocellulose membrane $(0.45 \mu \mathrm{M}$ diameter $)$ using a vacuum device, followed by 2 washing steps with ice cold buffer $B$. Membranes were exposed to phosphorimaging screens for $1 \mathrm{~h}$ and quantified with a phosphoimager.

Reporting summary. Further information on experimental design is available in the Nature Research Reporting Summary linked to this article.

\section{Data availability}

All sequencing data generated in this study have been deposited at the European Nucleotide Archive (ENA) and can be accessed with the number PRJEB24915. Al other data are available from the corresponding authors on request. A reporting summary for this article is available as Supplementary Information file.

Received: 21 February 2018 Accepted: 3 December 2018 Published online: 10 January 2019

\section{References}

1. Fenn, K. \& Matthews, K. R. The cell biology of Trypanosoma brucei differentiation. Curr. Opin. Microbiol. 10, 539-546 (2007).

2. Clayton, C. E. Gene expression in Kinetoplastids. Curr. Opin. Microbiol. 32 46-51 (2016).

3. Palenchar, J. B. \& Bellofatto, V. Gene transcription in trypanosomes. Mol. Biochem. Parasitol. 146, 135-141 (2006).

4. Tschudi, C., Shi, H., Franklin, J. B. \& Ullu, E. Small interfering RNAproducing loci in the ancient parasitic eukaryote Trypanosoma brucei. BMC Genom. 13, 427 (2012).

5. Vasquez, J. J., Hon, C. C., Vanselow, J. T., Schlosser, A. \& Siegel, T. N. Comparative ribosome profiling reveals extensive translational complexity in different Trypanosoma brucei life cycle stages. Nucleic Acids Res. 42, 3623-3637 (2014)

6. Gebetsberger, J., Wyss, L., Mleczko, A. M., Reuther, J. \& Polacek, N. A tRNA derived fragment competes with mRNA for ribosome binding and regulates translation during stress. RNA Biol. 14, 1364-1373 (2017).

7. Gebetsberger, J., Zywicki, M., Kunzi, A. \& Polacek, N. tRNA-derived fragments target the ribosome and function as regulatory non-coding RNA in Haloferax volcanii. Archaea 2012, 260909 (2012).

8. Pircher, A., Bakowska-Zywicka, K., Schneider, L., Zywicki, M. \& Polacek, N. An mRNA-derived noncoding RNA targets and regulates the ribosome. Mol. Cell 54, 147-155 (2014).

9. Pircher, A., Gebetsberger, J. \& Polacek, N. Ribosome-associated ncRNAs: an emerging class of translation regulators. RNA Biol. 11, 1335-1339 (2014).

10. Zywicki, M., Bakowska-Zywicka, K. \& Polacek, N. Revealing stable processing products from ribosome-associated small RNAs by deep-sequencing data analysis. Nucleic Acids Res. 40, 4013-4024 (2012).

11. Czech, A., Wende, S., Morl, M., Pan, T. \& Ignatova, Z. Reversible and rapid transfer-RNA deactivation as a mechanism of translational repression in stress. PLoS Genet. 9, e1003767 (2013).

12. Emara, M. M. et al. Angiogenin-induced tRNA-derived stress-induced RNAs promote stress-induced stress granule assembly. J. Biol. Chem. 285, 10959-10968 (2010).

13. Lyons, S. M., Achorn, C., Kedersha, N. L., Anderson, P. J. \& Ivanov, P. YB-1 regulates tiRNA-induced stress granule formation but not translational repression. Nucleic Acids Res. 44, 6949-6960 (2016).

14. Mahboubi, H. \& Stochaj, U. Cytoplasmic stress granules: dynamic modulators of cell signaling and disease. Biochim. Biophys. Acta 1863, 884-895 (2017).

15. Kramer, S. et al. Heat shock causes a decrease in polysomes and the appearance of stress granules in trypanosomes independently of eIF2(alpha) phosphorylation at Thr169. J. Cell. Sci. 121, 3002-3014 (2008).

16. Best, A., Handoko, L., Schluter, E. \& Goringer, H. U. In vitro synthesized small interfering RNAs elicit RNA interference in african trypanosomes: an in vitro and in vivo analysis. J. Biol. Chem. 280, 20573-20579 (2005).

17. Ngo, H., Tschudi, C., Gull, K. \& Ullu, E. Double-stranded RNA induces mRNA degradation in Trypanosoma brucei. Proc. Natl Acad. Sci. USA 95, 14687-14692 (1998).

18. Nachtergaele, S. \& He, C. The emerging biology of RNA post-transcriptional modifications. RNA Biol. 14, 156-163 (2017). 
19. Guzzi, N. et al. Pseudouridylation of tRNA-derived fragments steers translational control in stem cells. Cell 173, 1204-1216 e1226 (2018).

20. Thuring, K., Schmid, K., Keller, P. \& Helm, M. Analysis of RNA modifications by liquid chromatography-tandem mass spectrometry. Methods 107, 48-56 (2016).

21. Rubio, M. A. et al. Editing and methylation at a single site by functionally interdependent activities. Nature 542, 494-497 (2017).

22. Hashem, Y. et al. High-resolution cryo-electron microscopy structure of the Trypanosoma brucei ribosome. Nature 494, 385-389 (2013).

23. Gunzl, A. The pre-mRNA splicing machinery of trypanosomes: complex or simplified? Eukaryot. Cell 9, 1159-1170 (2010).

24. Garcia-Silva, M. R. et al. A population of tRNA-derived small RNAs is actively produced in Trypanosoma cruzi and recruited to specific cytoplasmic granules. Mol. Biochem. Parasitol. 171, 64-73 (2010).

25. Lee, S. R. \& Collins, K. Starvation-induced cleavage of the tRNA anticodon loop in Tetrahymena thermophila. J. Biol. Chem. 280, 42744-42749 (2005).

26. Anderson, P. \& Ivanov, P. tRNA fragments in human health and disease. FEBS Lett. 588, 4297-4304 (2014).

27. $\mathrm{Fu}, \mathrm{H}$. et al. Stress induces tRNA cleavage by angiogenin in mammalian cells. FEBS Lett. 583, 437-442 (2009).

28. Yamasaki, S., Ivanov, P., Hu, G. F. \& Anderson, P. Angiogenin cleaves tRNA and promotes stress-induced translational repression. J. Cell Biol. 185, 35-42 (2009).

29. Thompson, D. M., Lu, C., Green, P. J. \& Parker, R. tRNA cleavage is a conserved response to oxidative stress in eukaryotes. RNA 14, 2095-2103 (2008).

30. Franzen, O. et al. The short non-coding transcriptome of the protozoan parasite Trypanosoma cruzi. PLoS. Negl. Trop. Dis. 5, el283 (2011).

31. Bayer-Santos, E., Lima, F. M., Ruiz, J. C., Almeida, I. C. \& da Silveira, J. F. Characterization of the small RNA content of Trypanosoma cruzi extracellular vesicles. Mol. Biochem. Parasitol. 193, 71-74 (2014).

32. Garcia-Silva, M. R. et al. Extracellular vesicles shed by Trypanosoma cruzi are linked to small RNA pathways, life cycle regulation, and susceptibility to infection of mammalian cells. Parasitol. Res. 113, 285-304 (2014).

33. Lambertz, U. et al. Small RNAs derived from tRNAs and rRNAs are highly enriched in exosomes from both old and new world Leishmania providing evidence for conserved exosomal RNA Packaging. BMC Genom. 16, 151 (2015).

34. Zheng, L. L. et al. Comparative transcriptome analysis of small noncoding RNAs in different stages of Trypanosoma brucei. RNA 19, 863-875 (2013).

35. Lyons, S. M., Gudanis, D., Coyne, S. M., Gdaniec, Z. \& Ivanov, P. Identification of functional tetramolecular RNA G-quadruplexes derived from transfer RNAs. Nat. Commun. 8, 1127 (2017).

36. Smith, T. K., Bringaud, F., Nolan, D. P. \& Figueiredo, L. M. Metabolic reprogramming during the Trypanosoma brucei life cycle. F1000Res. 6, 683 (2017). https://doi.org/10.12688/f1000research.10342.2.

37. Haussecker, D. et al. Human tRNA-derived small RNAs in the global regulation of RNA silencing. RNA 16, 673-695 (2010).

38. Martinez, G., Choudury, S. G. \& Slotkin, R. K. tRNA-derived small RNAs target transposable element transcripts. Nucleic Acids Res. 45, 5142-5152 (2017).

39. Thompson, D. M. \& Parker, R. The RNase Rnylp cleaves tRNAs and promotes cell death during oxidative stress in Saccharomyces cerevisiae. J. Cell Biol. 185, 43-50 (2009).

40. Cristodero, M. \& Polacek, N. The multifaceted regulatory potential of tRNAderived fragments. Non-coding RNA Investigation 1, 7 (2017).

41. Gebetsberger, J. \& Polacek, N. Slicing tRNAs to boost functional ncRNA diversity. RNA Biol. 10, 1798-1806 (2013).

42. Cognat, V. et al. The nuclear and organellar tRNA-derived RNA fragment population in Arabidopsis thaliana is highly dynamic. Nucleic Acids Res. 45, 3460-3472 (2017).

43. Soares, A. R. \& Santos, M. Discovery and function of transfer RNA-derived fragments and their role in disease. Wiley Interdisciplinary Rev. RNA 8, e1423 (2017). https://doi.org/10.1002/wrna.1423.

44. Kim, H. K. et al. A transfer-RNA-derived small RNA regulates ribosome biogenesis. Nature 552, 57-62 (2017).

45. Wirtz, E., Leal, S., Ochatt, C. \& Cross, G. A. A tightly regulated inducible expression system for conditional gene knock-outs and dominant-negative genetics in Trypanosoma brucei. Mol. Biochem. Parasitol. 99, 89-101 (1999).

46. Brun, R. \& Schonenberger. Cultivation and in vitro cloning or procyclic cultureforms of Trypanosoma brucei in a semi-defined medium. Short communication. Acta Trop. 36, 289-292 (1979).

47. Hirumi, H. \& Hirumi, K. Continuous cultivation of Trypanosoma brucei blood stream forms in a medium containing a low concentration of serum protein without feeder cell layers. J. Parasitol. 75, 985-989 (1989).

48. Beverley, S. M. \& Clayton, C. E. Transfection of Leishmania and Trypanosoma brucei by electroporation. Methods Mol. Biol. 21, 333-348 (1993).
49. Gebetsberger, J., Fricker, R. \& Polacek, N. cDNA library generation for the analysis of small RNAs by high-throughput sequencing. Methods Mol. Biol. 1296, 139-149 (2015).

50. Luidalepp, H., Berger, S., Joss, O., Tenson, T. \& Polacek, N. Ribosome shutdown by $16 \mathrm{~S}$ rRNA fragmentation in stationary-phase Escherichia coli. J. Mol. Biol. 428, 2237-2247 (2016).

51. Masella, A. P., Bartram, A. K., Truszkowski, J. M., Brown, D. G. \& Neufeld, J. D. PANDAseq: paired-end assembler for illumina sequences. $B M C$ Bioinforma. 13, 31 (2012).

52. Aslett, M. et al. TriTrypDB: a functional genomic resource for the Trypanosomatidae. Nucleic Acids Res. 38, D457-D462 (2010).

53. Dobin, A. et al. STAR: ultrafast universal RNA-seq aligner. Bioinformatics 29, 15-21 (2013).

54. Lowe, T. M. \& Eddy, S. R. tRNAscan-SE: a program for improved detection of transfer RNA genes in genomic sequence. Nucleic Acids Res. 25, 955-964 (1997).

55. Langenberger, D. et al. Evidence for human microRNA-offset RNAs in small RNA sequencing data. Bioinformatics 25, 2298-2301 (2009).

56. Robinson, M. D., McCarthy, D. J. \& Smyth, G. K. edgeR: a Bioconductor package for differential expression analysis of digital gene expression data. Bioinformatics 26, 139-140 (2010).

57. Erlacher, M. D., Chirkova, A., Voegele, P. \& Polacek, N. Generation of chemically engineered ribosomes for atomic mutagenesis studies on protein biosynthesis. Nat. Protoc. 6, 580-592 (2011).

58. Erlacher, M. D. et al. Chemical engineering of the peptidyl transferase center reveals an important role of the 2'-hydroxyl group of A2451. Nucleic Acids Res. 33, 1618-1627 (2005).

\section{Acknowledgements}

We thank Isabel Roditi for the siRNA constructs targeting TbDCL1 and TbDCL2, Mark Carrington and Susanne Kramer for DHH1 constructs, Anna Stocker for experimental help during her bachelor project, Yulia Gonskikh and Bernd Schimanski for help with HeLa in vitro translation and mRNA northerns, respectively. Our thanks are extended to Julia Reuther for yeast expertise. The work was primarily supported by the NCCR 'RNA \& Disease' funded by the Swiss National Science Foundation. Additional support from the Swiss National Science Foundation grant 31003A_166527 [to N.P.] is acknowledged.

\section{Author contributions}

R.F. and R.B. conducted the majority of the experiments and analyzed the data. M.F. and L.W. contributed to metabolic labeling experiments. M.Z. and H.L. performed the bioinformatics analyses. R.B., M.C. and O.J. performed all experiments for the revised version of this work. M.H. performed and analyzed the LC-MS/MS experiments. A.S. provided T. brucei expertise, analyzed the data and commented on the manuscript. N.P. conceived the study and together with M.C. designed the experiments, supervised the study, analyzed the data and wrote the final version of the manuscript.

\section{Additional information}

Supplementary Information accompanies this paper at https://doi.org/10.1038/s41467 018-07949-6.

\section{Competing interests: The authors declare no competing interests.}

Reprints and permission information is available online at http://npg.nature.com/ reprintsandpermissions/

Publisher's note: Springer Nature remains neutral with regard to jurisdictional claims in published maps and institutional affiliations.

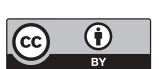

Open Access This article is licensed under a Creative Commons Attribution 4.0 International License, which permits use, sharing, adaptation, distribution and reproduction in any medium or format, as long as you give appropriate credit to the original author(s) and the source, provide a link to the Creative Commons license, and indicate if changes were made. The images or other third party material in this article are included in the article's Creative Commons license, unless indicated otherwise in a credit line to the material. If material is not included in the article's Creative Commons license and your intended use is not permitted by statutory regulation or exceeds the permitted use, you will need to obtain permission directly from the copyright holder. To view a copy of this license, visit http://creativecommons.org/ licenses/by/4.0/.

(C) The Author(s) 2019 